\title{
DNA-Based Scaffolds for Sensing Applications
}

\author{
Simona Ranallo, Alessandro Porchetta, ${ }^{*}(\mathbb{0}$ and Francesco Ricci*(i) \\ Department of Chemical Sciences and Technologies, University of Rome Tor Vergata, Via della Ricerca Scientifica 1, 00133 Rome,
} Italy

\section{CONTENTS}

DNA Nanotechnology for Sensing Applications $\quad 44$

Optical Structure-Switching DNA Scaffolds $\quad 45$

Antibody Detection $\quad 45$

DNA-Based Structure Switching Probes for Optical Antibody Detection

Nucleic Acid-Based Co-Localization Probes for Optical Antibody Detection

DNA-Based Scaffolds for Antibody-Controlled

Reactions, Logic Gates, and Circuits

DNA Scaffold Probes as Electrochemical Sensors

DNA-Based Switches for Electrochemical Antibody Detection

DNA Scaffolds for Electrochemical Antibody

Detection Based on Steric Hindrance

DNA Nanostructures as Scaffolds for Sensing

Applications

Multienzyme Complexes on Two-Dimensional (2D) and Three-Dimensional (3D) DNA Origami Scaffolds

DNA Tetrahedral Scaffolds for Sensing Applica-

tions

Proximity-Based Assembly of DNA Scaffolds for Sensing Applications

DNA Scaffolds for Creating Synthetic Nanopores for Single-Molecule Biosensing

Conclusions

Author Information

Corresponding Authors

ORCID

Notes

Biographies

Acknowledgments

References

\section{DNA NANOTECHNOLOGY FOR SENSING APPLICATIONS}

DNA nanotechnology employs synthetic nucleic acid strands to design and engineer nanoscale structural and functional systems of increasing complexity that may find applications in sensing, ${ }^{1-7}$ computing, ${ }^{8-10}$ molecular transport, ${ }^{11-13}$ information processing, ${ }^{14}$ and catalysis. ${ }^{15,16}$ Several features make synthetic DNA a particularly appealing and advantageous biomaterial for all the applications mentioned above but more specifically for sensing. First, synthetic DNA sequences, especially if of limited length ( $<100$ nucleotides), have highly predictable interactions and thermodynamics. This allows the development of spatiotemporally controlled nanostructures with quasi-Armstrong precision and the engineering of supramolecular devices with well-controlled secondary structures. ${ }^{17-22}$ DNA is also quite easy and inexpensive to synthesize: currently the cost of $150 \mu \mathrm{g}$ of an unmodified single-stranded DNA strand of 20 nucleotides is $\sim 8$ euros if it is purchased from one of the many commercial vendors available in the market. Finally, DNA is relatively stable compared to other biomolecules like enzymes or antibodies. The other important feature of synthetic DNA is the wide range of possibilities that it offers for sensing applications if it is used as recognition element. Of course, the most obvious use of a single-stranded synthetic DNA sequence as a recognition element is for the detection of a specific target complementary sequence. Countless applications of such a use, especially if coupled with polymerase chain reaction (PCR), have been reported to date, which resulted in many commercially available sensing devices. ${ }^{23,24}$ Synthetic DNA can also be used as a recognition element for targets other than DNA. This is the case, for example, of DNA aptamers, a class of highaffinity nucleic acid ligands, which are selected through alternate cycles in vitro to bind a specific target molecule. ${ }^{25-29}$ To date, thousands of DNA and RNA aptamers that bind to specific targets have been selected, including small molecules, proteins, peptides, bacteria, virus, and live cells. ${ }^{30-32}$ Other aptamers can bind to surface molecules and membrane proteins of live cells. ${ }^{33-35}$ A DNA aptamer is usually a short DNA sequence ( $<100$ nucleotides) that can bind its specific target with high affinity (nanomolar to micromolar) and high specificity. While the affinity of the aptamers is usually not as high as that of other biomolecular recognition elements (i.e., antibodies), there are some advantages connected with their use, including the lower cost and higher stability. Synthetic DNA can also be used as a recognition element to detect metal ions through the use of thymine-thymine (T-T) and cytosinecytosine (C-C) mismatches, which specifically bind mercury(II) $)^{36-38}$ and silver(I) ${ }^{39,40}$ ions, respectively, or through the use of copper-dependent DNAzymes. ${ }^{41}$ Similarly, nonconventional DNA interactions can be used to rationally design $\mathrm{pH}$ sensitive DNA switches that can be used as nanometer scale pH meters. ${ }^{42-44}$ Such probes typically exploit DNA secondary structures that display $\mathrm{pH}$ dependence due to the presence of specific protonation sites. These structures include Imotif, ${ }^{45-50}$ inter- and intramolecular triplex DNA, ${ }^{51-55}$ DNA tweezers, ${ }^{56}$ and catenanes. ${ }^{57}$ Recently, we have also reported on the rational design of programmable DNA-based nanoswitches whose closing and/or opening can be triggered over specific different $\mathrm{pH}$ windows by simply changing the relative

Special Issue: Fundamental and Applied Reviews in Analytical Chemistry 2019

Published: December 1, 2018 

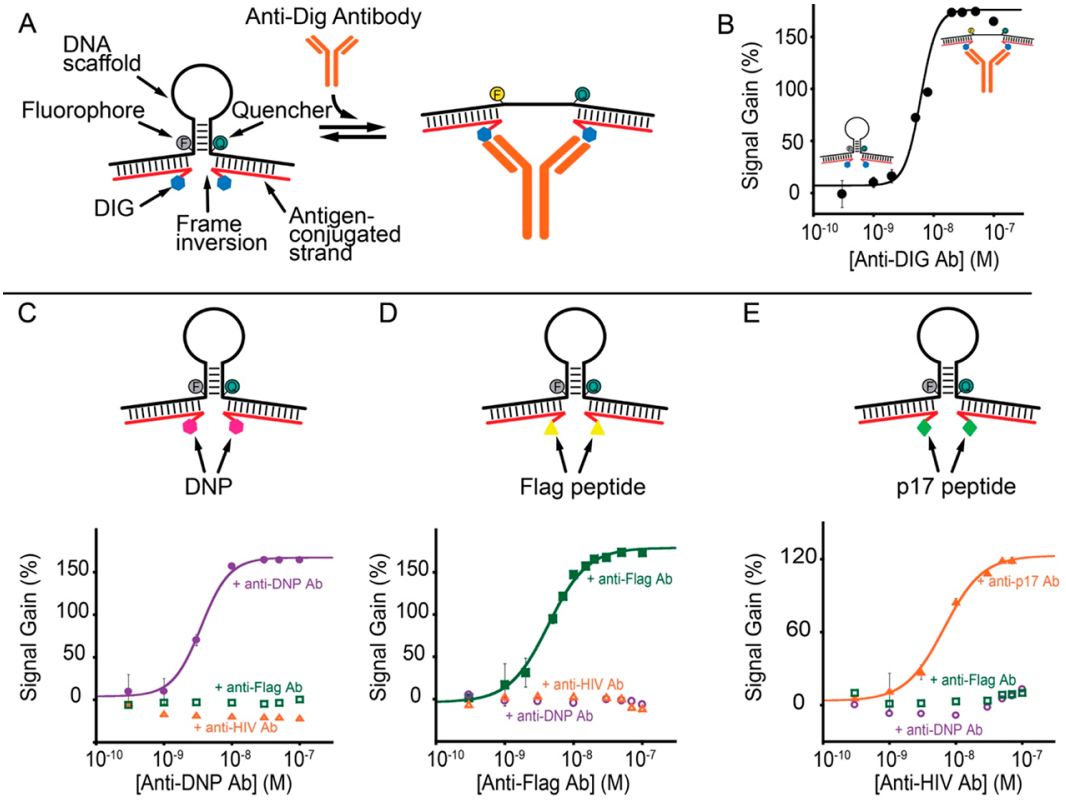

Figure 1. DNA-based structure switching probes for optical antibody detection. (A) The optical antibody-switch platform is designed to adopt a two-tailed stem-loop conformation in the absence of the target antibody. The two single-stranded tails act as an anchoring strand for DNA complementary sequences that are conjugated at one end with an appropriate recognition element (i.e., digoxigenin antigen) for the target antibody (anti-digoxigenin antibody). The binding of one copy of a target antibody to the two recognition elements causes a conformational change resulting in the opening of the stem-loop conformation and in an increase in the fluorescence signal intensity. (B) The antibody-switch sensor detects antidigoxigenin antibodies at low nanomolar concentrations. (C-E) The modular nature of the platform allows the detection of different targets by changing the recognition element [C, dinitrophenol (DNP); D, eight-residue FLAG peptide; E, 13-residue epitope excised from HIV protein p17] in a nanomolar concentration range, without any significant cross-reactivity with the other nonspecific targets. Reproduced from A Modular, DNABased Beacon for Single-Step Fluorescence Detection of Antibodies and Other Proteins. Ranallo, S.; Rossetti, M.; Plaxco, K. W.; Vallée-Bélisle, A.; Ricci, F. Angew. Chem., Int. Ed. 2015, Vol. 54, Issue 45 (ref 89). Copyright 2015 Wiley.

content of TAT/CGC triplets in the switches. ${ }^{58}$ Finally, DNA can be employed as a convenient recognition element for the detection of transcription factors, proteins that control the transcription of genetic information and specifically recognize double-stranded or single-stranded DNA and RNA sequences. $^{59-63}$

The examples of DNA-based sensors described above, in which DNA itself is used as recognition element, have been recently summarized in several extremely complete reviews. $^{64-68}$ Although interesting for sensing applications, these examples also demonstrate that the range of targets that can be detected with DNA as a recognition element is limited, and this can ultimately hamper further progress in the field of DNA-based sensors. Recently, however, a novel use of synthetic DNA has proven to be extremely advantageous for analytical use. DNA, in fact, contains several functional groups that make it quite straightforward to modify a synthetic nucleotide sequence at both ends or internally. A variety of additional reactive groups can be introduced into DNA sequences, and most of these modifications are currently available in the catalogues of synthetic DNA oligonucleotide commercial vendors. For sensing applications, these functional groups can be used to conjugate signaling moieties (for example, fluorophore/quencher pairs or electrochemical redox labels) or anchoring tags (for example, thiol groups for attachment to a gold electrode surface). As we will show during the course of this review, this chemical versatility can also be used to attach and conjugate different recognition elements to a synthetic DNA sequence, thus widely expanding the range of targets that could be detected with DNA-based sensors. In these cases, DNA is thus simply used as a versatile scaffold that allows the attachment and conjugation of a wide range of small and large molecules with high accuracy and precision. This review intends to summarize the recent advancements made in this direction by describing results achieved in the past 4 years and will serve as an important demonstration that synthetic DNA can indeed be used as a versatile scaffold for a wide range of sensing applications that are not limited to the targets that are usually recognized by DNA probes. We will not focus on the conjugation strategies and protocols used; we direct the readers to recent specific reviews on this subject. ${ }^{69,70}$ We will instead focus on the practical analytical applications of DNA scaffold systems. The examples we have included in this review can be divided into three major classes. Initially, we will describe DNA-based systems belonging to the class of structure-switching probes that are mostly based on optical detection. We will then describe DNA-scaffolded electrochemical sensors and finally show the potential of DNA nanostructures (origami) to position recognition elements in a highly precise way.

\section{OPTICAL STRUCTURE-SWITCHING DNA SCAFFOLDS}

Antibody Detection. The detection of specific antibodies and other diagnostic proteins plays a crucial role in the diagnosis of many diseases, infections, and pathologies. ${ }^{71,72}$ Despite their widespread use, however, current methods for the quantitative detection of specific antibodies, including enzyme-linked immunosorbent assays (ELISAs) and Western blots, remain cumbersome, laboratory-bound processes ${ }^{73,74}$ because the formation of antibody-antigen complexes is not linked to any easily measurable output. For this reason, current 
methods for antibody detection typically employ "sandwich assay" formats in which in a multistep, wash-intensive process a conjugated secondary antibody or antigen is used to generate an observable signal. ${ }^{75-77}$ While these limitations have only modestly impacted the use of these approaches in industrialized countries, they significantly limit the applicability of these techniques in point-of-care applications and in the developing world. $^{78,79}$ To ensure rapid appropriate care for patients, simple, inexpensive, and quantitative tools for the detection of specific antibodies are thus urgently needed. Apart from the obvious application for disease diagnostics, platforms for antibody detection could also be used for other important purposes. In recent years, for example, immunotherapy has attracted a great deal of interest because of its promising expectations for the treatment of various forms of cancer or other diseases. ${ }^{80-82}$ Indeed, immunotherapy represents a powerful tool, either as a monotherapy or as a combination therapy with chemotherapy or radiation. At the end of 2016, nearly 60 antibody drugs had been approved by the Food and Drug Administration, and many more are currently in clinical trials. ${ }^{83}$ Recently, bioengineered bispecific antibodies (BsAbs) containing two different binding sites within a single molecule seem to offer the potential to improve therapeutic efficacy and promise to be the next generation of immunotherapy. ${ }^{84,85}$ From this perspective, it would be extremely important to be able to measure, during immunotherapy treatment, the levels of therapeutic antibodies at designated time intervals and to maintain a constant drug concentration in a patient's bloodstream, thereby optimizing individual dosage regimens and clinical outcomes in patients. ${ }^{86-88}$ For the reasons mentioned above, point-of-care (POC) methods for the detection and quantification of therapeutic antibodies would improve the characterization and monitoring of immunotherapies, improving their efficacy with subsequent great societal and medical benefits.

Motivated by the considerations mentioned above, researchers have recently been strongly devoted to employing the advantageous features of synthetic DNA to design and develop rapid and sensitive analytical platforms for antibody detection. In all of these examples, DNA is not employed as a recognition element but merely as a scaffold to attach the specific recognition element and to signal the presence of the target antibody through a conformational change that takes advantage of the spatial geometry common to most antibodies. All IgG and IgE antibodies, in fact, share the same y-shaped structure with two identical binding sites separated by approximately $10-12 \mathrm{~nm}$. This simple and yet often overlooked feature of antibodies has been instrumental in cleverly designing novel direct systems for antibody detection based on the use of synthetic DNA scaffolds and different sensing strategies.

DNA-Based Structure Switching Probes for Optical Antibody Detection. We have recently rationally designed a DNA-based platform for the optical single-step and quantitative detection of antibodies based on a target-induced conformational change mechanism. ${ }^{89}$ Our analytical platform, which we named antibody-switch (Figure 1A), is comprised of a 66-nucleotide scaffold DNA sequence (black) containing two five-nucleotide internal, complementary regions. This scaffold forms, in the absence of the target antibody, a two-tailed stem-loop structure (Figure 1A). A fluorophore/quencher pair was internally conjugated at two thymines at the end of the stem portion so that the scaffold provides a weak fluorescent signal in the stem-loop configuration. The two single-stranded tails of the scaffold act as anchoring strands for the hybridization of two DNA complementary sequences that are conjugated at one end with an appropriate recognition element (antigen) for the target antibody. To avoid the use of two different antigen-conjugated strands, the scaffold strands were designed to have a $5^{\prime}-3^{\prime}$ frame inversion at one end of the stem. This ensures that the two tails meet "head to head" ( 3 '-end to 3 '-end), thus allowing a single recognition elementmodified strand sequence to populate both recognition sites. The binding of one copy of a target antibody to the two recognition elements on the scaffold causes the opening of the stem-loop conformation, thus resulting in an increase in the intensity of the fluorescence signal due to the fact that the fluorophore is forced away from the quencher. In this example, the modularity of DNA is thus used to design a sensor that is composed of multiple units each with a different purpose. The scaffold unit provides signaling and the conformational switching mechanism. The antigen-conjugated strands, instead, provide the recognition ability for the target antibody. While the sensing idea of such a platform is simple, its rational design and optimization is not straightforward and requires the careful observation of the following general rules. The first rule applies to all structure-switching sensors and is related to sensitivity. The thermodynamic switching equilibrium of the stem-loop scaffold between the closed and open conformation is in fact crucial to achieving a high sensitivity and a good signal-tonoise ratio. In this specific case, a weak background and a large signal change can be achieved when the switching equilibrium is shifted toward the closed conformation (i.e., when the equilibrium switching constant, $K_{\mathrm{S}}=$ [open conformation]/ [closed conformation], is <0.1). ${ }^{90}$ However, an overstabilization of the closed conformation also increases the energetic barrier that antibody binding must overcome to cause the conformational switch, thus affecting sensitivity. A compromise in the optimization of the switch is thus required, and usually, the lowest limits of detection can be achieved with a $K_{\mathrm{S}}$ of $\sim 1$, which gives a maximum signal gain of $50 \%$ (because $50 \%$ of the switch is already in the "open" conformation in the absence of input) while decreasing the observed affinity only 2 -fold compared to the intrinsic affinity of the target antibody. ${ }^{61,91}$

The second rule that needs to be considered in the design of antibody switches is the distance that the two recognition elements should span in the open conformation to allow optimal binding of the antibody. In this regard, we note that the hinge region that links the $F_{c}$ and $F a b$ portions of an antibody is a flexible tether that allows a quite independent movement of the two Fab arms, thus making the distance between the two binding sites (present at the end of the Fab arms) quite variable. ${ }^{92,93}$ Despite this, the common $y$-shaped structural view of an IgG or IgE antibody shows the two binding sites separated by approximately 10-12 nm. This distance should thus be taken as a reference for the rational design of the antibody-switch.

Both of the design rules described above can be easily met by taking advantage of the versatility of synthetic DNA, which allows one to fine tune the stability of the stem-loop conformation by simply changing the length of the stem and its TA versus GC content and to span a quite precise distance between the recognition elements by changing the number of nucleotides in the loop. To optimize the switch according to the rules mentioned above, digoxigenin was initially used as antigen and anti-digoxigenin antibodies were employed as 

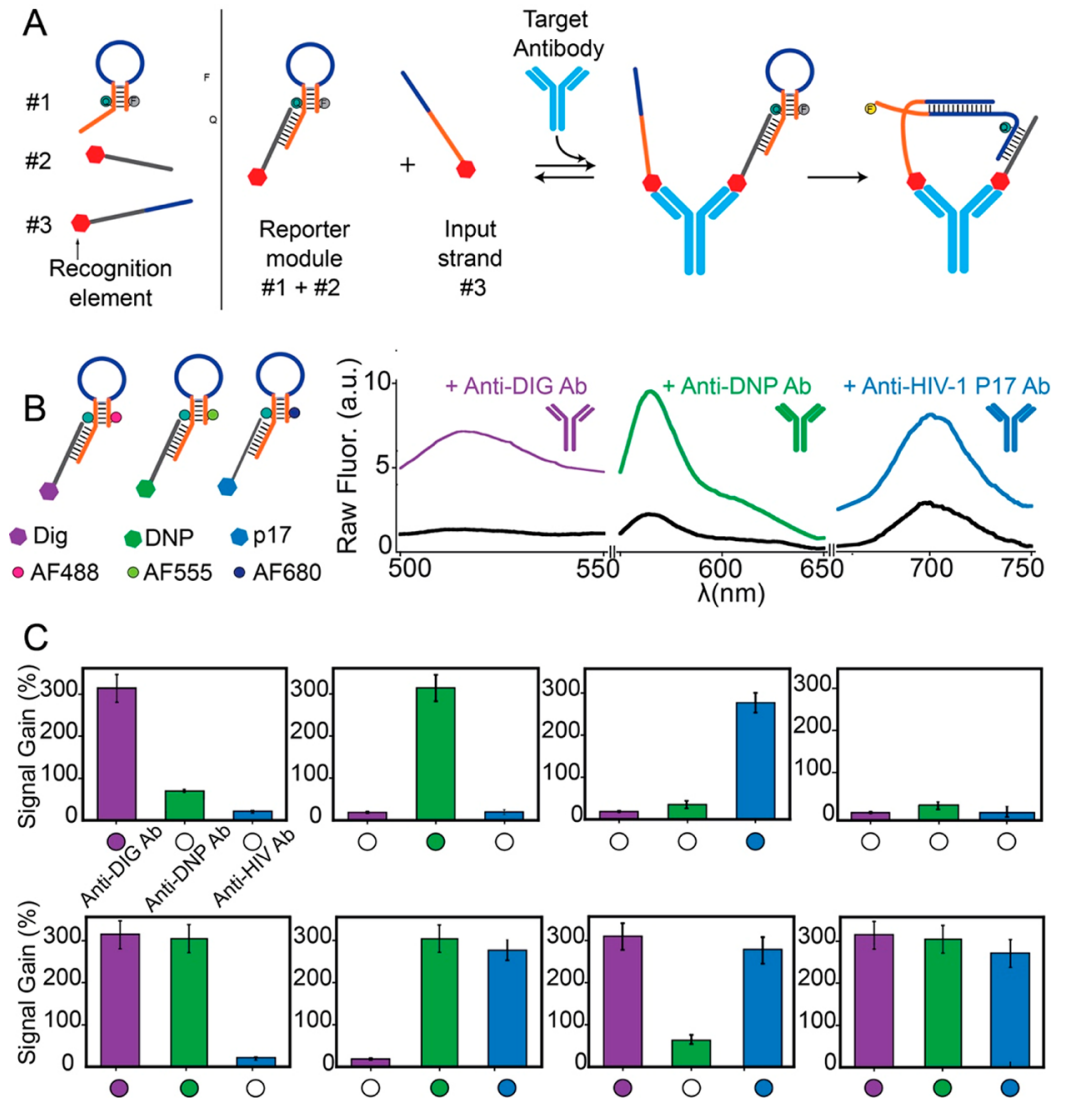

Figure 2. Nucleic acid-based co-localization probes for optical antibody detection. (A) Here the DNA scaffold is employed in conjunction with an antibody-induced co-localization mechanism. The modular nature of the recognition platform allows for the detection of any antibody for which an antigen can be conjugated to a nucleic acid strand. (B) Simultaneous orthogonal multiplexed detection of anti-DIG, anti-DNP, and anti-HIV-1 p17 antibodies using DNA scaffolds modified with three different fluorophore/quencher pairs. (C) Signal gain of the three nanoswitches obtained by adding each antibody $(50 \mathrm{nM})$ in different combinations. Filled and empty circles are used to identify the antibody added in solution. Reproduced from Porchetta, A.; Ippodrino, R.; Marini, B.; Caruso, A.; Caccuri, F.; Ricci, F. Programmable Nucleic Acid Nanoswitches for the Rapid, Single-Step Detection of Antibodies in Bodily Fluids. J. Am. Chem. Soc. 2018, 140, 947-953 (ref 98). Copyright 2015 American Chemical Society.

targets. While we note that this is not a clinically relevant target, the use of the digoxigenin/anti-digoxigenin couple is perfect for optimization purposes for the following reasons. First, digoxigenin is a small molecule that does not affect the overall stability of the stem-loop scaffold. Second, digoxigenin is a widely used hapten in biotechnology ${ }^{94}$ and contains more than one functional group that allows a simple and inexpensive conjugation to synthetic DNA (Figure 1B).

Once the antibody-switch is optimized, its modular nature offers the possibility of generalizing the platform for the detection of other antibodies. Indeed, by simply changing the recognition element on the scaffold, one can create a platform for the measurement of potentially any antibody. This was demonstrated by using as recognition elements not only small molecules but also peptides. Specifically, the small molecule dinitrophenol (DNP), ${ }^{95}$ which is recognized by the anti-DNP antibody and the Flag ${ }^{96}$ and p17 peptides, ${ }^{97}$ recognized by the anti-Flag antibody and the anti-HIV antibody, respectively, were employed (Figure $1 \mathrm{C}-\mathrm{E}$ ). All the switch variants respond rapidly $(<10 \mathrm{~min})$ to their specific targets with low nanomolar affinity for their targets, with a comparable efficiency in $90 \%$ of blood serum, and very important for sensing purposes, they did not exhibit any significant cross-reactivity with the other targets. Such an antibody-switch platform presents several advantages that make it well-positioned among other direct assays and suggest that it may be of utility in a range of different applications such as point-of-care diagnostics and in vivo imaging. It is versatile and can be easily adapted to the detection of a wide range of antibodies. It is rapid and reagentless and does not require washing steps. The use of synthetic DNA makes it also quite stable and cost-effective. Obviously, together with the positive features mentioned above, there are limitations that should be considered. First, the lack of any amplification step makes the detection limit achievable with this platform not comparable to that observed with other homogeneous assays for the detection of antibodies based on enzyme amplification steps (e.g., ELISA). In this regard, we note that the detection limit achieved with the antibody-switch is in the low nanomolar range, which represents the limit of detection of commonly used fluorescence detectors. Second, the platform is obviously sensitive to the size of the antigen employed, the largest antigens employed so far being peptides of $<13$ residues ( $p 17$ ). The use of larger recognition elements (for example, entire proteins) would surely result in the need for reoptimization of the entire scaffold unit.

Nucleic Acid-Based Co-Localization Probes for Optical Antibody Detection. To overcome the practical limitations affecting the platform described above and to improve the advantages of using DNA-based switching probes for diagnostic applications, a new approach that couples the positive features of DNA-based conformational switching 
probes (nanoswitches) with those of co-localization approaches was recently proposed by our group. ${ }^{98}$ In this specific case, the spatial geometry of the target antibody is in fact used to induce an increase in the effective concentration of two DNA-based modules each conjugated with a recognition element (i.e., an antigen). Considering also in this case a distance of approximately $10-12 \mathrm{~nm}$ between the two binding sites of a single antibody, one can predict that the two moieties bound to a single antibody will be confined in a zeptoliter volume thus leading to an effective concentration in the high micromolar range. ${ }^{99}$ This increase in effective concentration can be employed to trigger a signaling reaction that, otherwise, will be silent. The system is composed of two synthetic nucleic acid modules (Figure 2A). A first module (reporter module) that comprises a fluorophore/quencher-modified DNA hairpin (\#1) is designed to hybridize with a synthetic nucleic acid strand (\#2) conjugated to an appropriate recognition element (an antigen). The second module (input module) is conjugated with another copy of the antigen and contains a domain complementary to the loop sequence of strand \#1. Upon binding to the target antibody, the reporter and input modules are co-localized in a confined volume, thereby increasing their local concentrations and allowing their efficient hybridization. Such antibody-induced hybridization forces the opening of the hairpin, enhancing the switch's fluorescence (300-fold increase) and allowing for the rapid (within $2 \mathrm{~min}$ ) and sensitive detection of the antibody in the low nanomolar range. The modular nature of the platform permits one to easily change the recognition element in the two modules, allowing the detection of different antibodies (Figure 2B). By using different fluorophore/quencher pairs, the multiplexed detection of different target antibodies in an orthogonal way was also demonstrated (Figure 2C). The platform has been employed to monitor the immune response elicited from HIVpositive patients enrolled in a medical trial and treated with a peptide-based (AT20 peptide) phase I therapeutic vaccine. Recently, the use of this platform has also been demonstrated for the detection of small molecules through a competitive assay. Specifically, a competitive fluorescence single-step detection of environmentally relevant small target analytes was developed. ${ }^{100}$ The modular system consists of the same two modules described above that are designed to be colocalized in a confined volume in the presence of a target antibody. The presence of free recognition element molecules (i.e., antigen) competing for the same antibody binding prevents the reporter and input modules from being in the proximity, which leads to a decreased fluorescence emission.

Similar proximity-based strategies have been demonstrated in the past 20 years for analytical purposes. In this regard, one of the main representative examples is the protein-fragment complementation assay that allows one to monitor bimolecular interactions through the use of a reporter protein initially split into two halves, each one tethered to a specific recognition element. The interaction between the two recognition elements, or with a third interactive species, induces the colocalization and the assembly of the two protein halves to constitute the active signaling protein. Inspired by this, an antibody-templated assembly of a functional RNA structure was recently proposed by our group. ${ }^{101}$ To do so, a Spinach aptamer (a GFP-like RNA mimic), ${ }^{102}$ which specifically binds to a synthetic copy [3,5-difluoro-4-hydroxybenzylidene imidazoline (DFHBI)] of the natural GFP fluorophore, leading to the display of GFP-like fluorescence properties, has been split and conjugated with a pair of antigens. The binding of the target antibody to the two RNA-conjugated antigen strands allows the constitution of the active conformation of the Spinach aptamer and leads to efficient binding of DFHBI with a consequent increase in the intensity of the fluorescence signal. The templated assay was tested for the detection of two different antibodies (anti-digoxigenin and anti-dinitrophenol antibodies), producing an affinity in the low nanomolar range. ${ }^{101}$ The performance of the assembly process was also tested in RPMI cell culture medium and HeLa cell whole lysates, and this test revealed similar performances in terms of the sensitivity and observed signal, suggesting the potential use of this assay for bioimaging and bioanalytical purposes.

DNA-Based Scaffolds for Antibody-Controlled Reactions, Logic Gates, and Circuits. Apart from the analytical applications described above, DNA-based scaffolds that respond to antibodies or other macromolecular targets can also be used to control reactions, molecular circuits, logic gates, and load/release of molecular cargos. Gothelf and co-workers proposed a general method that employs DNA-based strand displacement competition reactions (SDCs) for the detection of small molecules and proteins. ${ }^{103}$ The assay principle is based on the conjugation of a recognition element to a DNA strand involved in a classic strand displacement reaction. The binding of a macromolecular target (i.e., a protein or an antibody) to such a recognition element shifts the equilibrium of the DNAbased strand displacement competition reaction, and this results in a measurable optical output. The authors demonstrated nanomolar detection of antibodies or protein targets and, through a competitive approach, the nanomolar detection of small molecules such as biotin, digoxigenin, vitamin $\mathrm{D}$, and folate, in buffer and in plasma. The method is flexible and provides an interesting way to use DNA as a scaffold for sensing applications.

In a follow-up work, Gothelf and co-workers demonstrated the development of hybridization chain reaction (HCR) for the detection of different targets. ${ }^{104}$ The sensing principle relies on the use of DNA reaction initiator strands conjugated with small molecule ligands. The binding of the target protein to this recognition element provides a steric hindrance to the initiator strand resulting in a retarded HCR. This assay allows a response within nanomolar concentrations of the small molecules in $<5$ min even in $50 \%$ human plasma.

The group of M. Merkx, which pioneered the development of protein-switches for antibody detection, ${ }^{105-108}$ has recently demonstrated the design of bivalent peptide-DNA conjugates that can act as molecular locks to control the activity of an antibody. They originally designed dsDNA bivalently conjugated with two antigen peptides spanning a distance of 10$12 \mathrm{~nm}$. These bivalent peptide-dsDNA conjugates could bind to the target antibody 500-fold more strongly than a monovalent peptide, allowing effective blocking of the antigen binding sites in a noncovalent manner. ${ }^{109}$ The cleavage of the linker between the peptide epitope and the DNA could restore the activity of the antibody. The same group extended this approach by designing novel DNA-peptide conjugates that could block the antibody activity through hybridization. This allowed the easy activation and/or inhibition of the antibody by toehold strand displacement reactions (Figure 3A). ${ }^{110}$ Employing yeast as a cellular model system, reversible control of antibody targeting was demonstrated with low nanomolar concentrations of peptide-DNA locks and oligonucleotide displacer strands (Figure 3B). Introduction of two different 

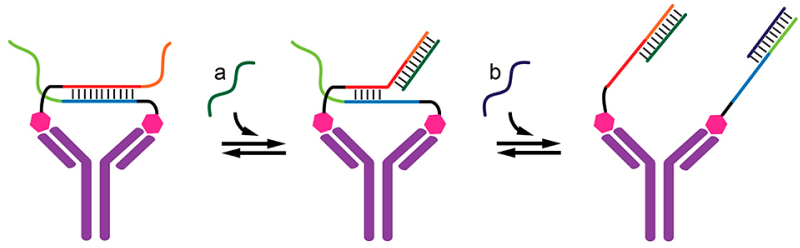

B

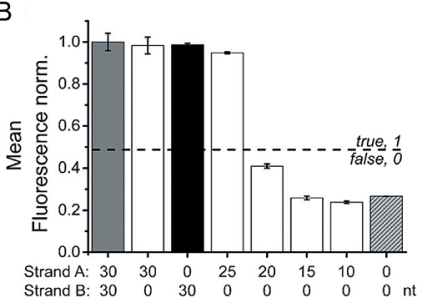

C

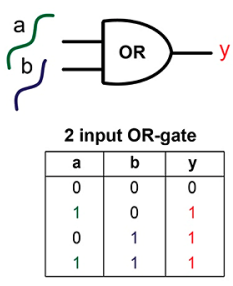

Figure 3. DNA-based scaffolds for antibody-controlled reactions, logic gates, and circuits. (A) DNA-based bivalent ligands are employed to bridge the two binding sites of a monoclonal antibody and control its activity. (B-C) Using two DNA input strand (a, b) and by exploiting toehold strand displacement reaction, OR- or ANDlogic gate DNA-based operations are demonstrated to control the activity of antibodies. Reproduced from Antibody Activation using DNA-Based Logic Gates. Janssen, B. M.; van Rosmalen, M.; van Beek, L.; Merkx, M. Angew. Chem., Int. Ed., Vol. 54, Issue 8 (ref 110). Copyright 2015 Wiley.

toehold strands on the peptide-DNA lock allowed signal integration of two different inputs, yielding logic OR- and AND-gates (Figure 3C). One limitation of this platform is that it contains an inherent design constraint. The monovalent affinity of the antibody-epitope interaction should be significantly lower than the effective concentration provided by the dsDNA linker, which has been estimated to be approximately $10 \mathrm{mM}$, but not so low as to block antibody binding to a cell surface receptor as a monovalent ligand. A similar approach, named antibody-templated strand exchange (ATSE), was used to translate the presence of an antibody into a single-stranded DNA output and promote DNA strand exchange reactions. ${ }^{111}$ Merkx and co-workers have performed a detailed characterization of the ATSE reaction that allowed the establishment of a comprehensive model describing the kinetics and thermodynamics of ATSE as a function of toehold length, antibody-epitope affinity, and concentration. Such antibody-controlled DNA-based molecular circuits introduce complex signal processing capabilities beyond those that can be achieved in conventional immunoassays and thus might prove particularly suitable for antibody-based diagnostics. The authors demonstrated also in this case logic gates and multiplex detection but other types of signals could be envisioned, including thresholding, signal amplification, feedback, and signal modulation.

Our group has also recently demonstrated the possibility of using DNA scaffolds to promote the release of molecular cargos with antibodies. ${ }^{112}$ More specifically, we have engineered a modular DNA-based nanomachine designed to load a DNA strand and release it exclusively in the presence of a specific antibody. The system is based on a DNA sequence that can bind a specific DNA cargo strand forming a triplehelix structure involving both Watson-Crick and Hoogsteen interactions. The DNA sequence presents a pair of antigens at the two ends that act as recognition elements for a specific antibody (Figure 4A). The binding of the antibody to the two

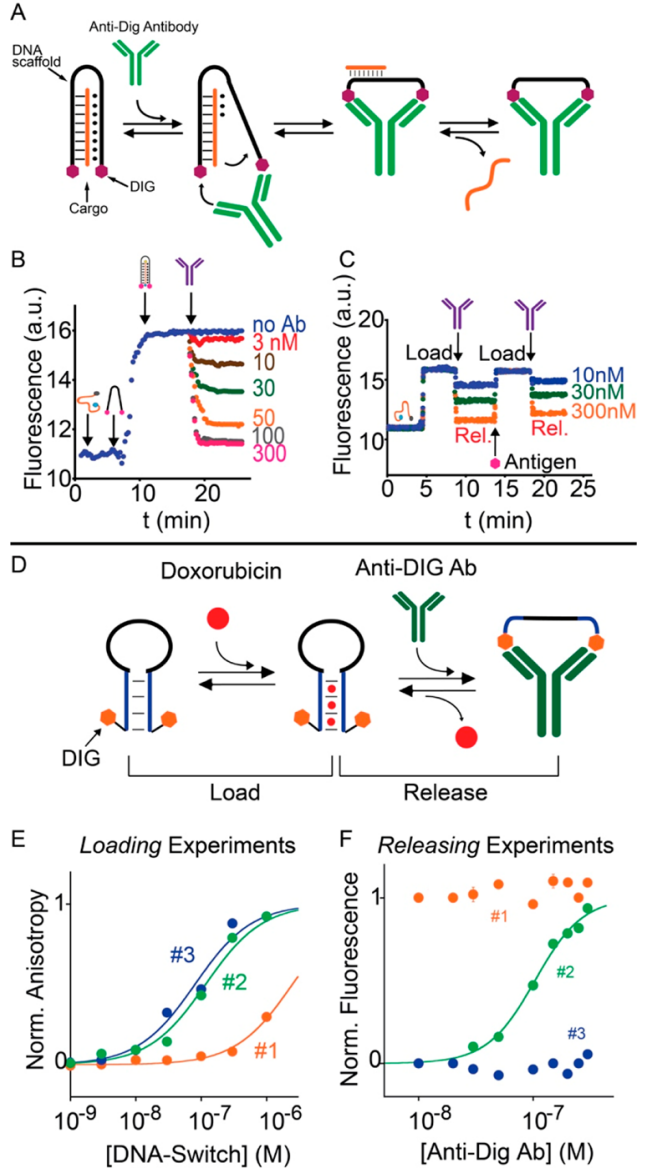

Figure 4. Antibody-controlled DNA nanoswitches for controlled release of molecular payloads. (A) DNA-based nanomachine that can reversibly load and release a molecular cargo upon binding to a specific antibody. A DNA strand (black) is designed to hybridize a DNA cargo strand thus forming a triplex structure. The DNA scaffold is also conjugated with two antigens (purple hexagons). Antibody binding disrupts the triplex conformation, allowing the release of the cargo strand. (B) Fine modulation of release of the cargo by varying the concentration of the triggering antibody. (C) Reversible load and release of the molecular cargo by cyclically adding the triggering antibody and the free antigen in a solution containing both the nanomachine and the cargo strand. (D) Stem-loop antibodyregulated DNA nanoswitches modified with two antigen tags at the two extremities and containing the intercalating domain for doxorubicin. The binding of the specific antibodies to the two antigen moieties pushes the conformational equilibrium between the "Load" and "Release" state toward the latter, thus triggering the release of doxorubicin. (E) Variants with different stabilities of the "Load" state show different affinities for doxorubicin. (F) Doxorubicin release at increasing concentrations of the antibody reflects the different behavior of the three variants. Panels $\mathrm{A}-\mathrm{C}$ reprinted by permission from Macmillan Publishers Ltd. Ranallo, S.; PrévostTremblay, C.; Idili, A.; Vallée-Bélisle, A.; Ricci, F. Nat. Commun. 2017, 8, 15150 (ref 112). Copyright 2017. Panels D-F reproduced from Rossetti, M.; Ranallo, S.; Idili, A.; Palleschi, G.; Porchetta, A.; Ricci, F. Chem. Sci. 2017, 8, 914-920 (ref 113), with permission of The Royal Society of Chemistry.

antigen tags induces a conformational change that destabilizes the Hoogsteen interactions and leads to the release of the cargo (Figure 4B). We have demonstrated the release of a DNA cargo strand employing three different triggering antibodies with high specificity and selectivity even in complex media ( $90 \%$ serum). We have also demonstrated that our 
nanomachine can load and release the cargo in a reversible fashion by cyclically adding the specific antibody and the free antigen (Figure 4C). The modular nature of our approach allows the development of nanomachines that can respond to different antibodies in an orthogonal way and to substitute the recognition module through a toehold-mediated strand displacement reaction.

Using a similar approach, we have also recently demonstrated the antibody-triggered release of doxorubicin from a DNA-based nanoswitch. ${ }^{13}$ The nanoswitch is designed to adopt a stem-loop conformation and is used as scaffold to attach the specific recognition elements (i.e., antigens) at both ends. The nanoswitch mutually adopts two conformations: a "Load" conformation containing a doxorubicin-intercalating domain and a "Release" conformation stabilized upon binding of the antibody to the two antigen tags (Figure 4D). The binding of the specific antibody, in fact, causes a conformational change that opens the stem-loop conformation allowing the release of the intercalated doxorubicin (Figure 4E,F). We have achieved a controlled release of the molecular cargo in an antibody concentration-dependent fashion. Our approach augments the current tool kit of smart drug release mechanisms regulated by different biological inputs.

The possibility of using antibodies as new triggering inputs to control DNA-based reactions and nanomachines represents a great novelty in the field of functional DNA nanotechnology and may find applications in point-of-care diagnostics, controlled drug release, and in vivo imaging. Moreover, the control over the function of the antibody-released DNA strand open new routes to assembly dynamic and static DNA-based nanostructures upon clinical inputs.

\section{DNA SCAFFOLD PROBES AS ELECTROCHEMICAL SENSORS}

DNA-Based Switches for Electrochemical Antibody

Detection. The past few years have witnessed an explosion in the number of electrochemical sensors targeting antibodies. $^{75,114-116}$ This interest is mainly due to the many positive features of electrochemical detection that include their low level of interference in complex matrices, the low cost of instrumentation, and the possibility of having mass-producible sensors that make these platforms particularly suitable for point-of-care applications..$^{117-121}$ One of the first demonstrations in this direction is represented by a versatile, DNA-based electrochemical platform for the single-step measurement of specific antibodies directly in undiluted whole blood at clinically relevant low nanomolar concentrations. ${ }^{122}$ A hairpin DNA nanoswitch that acts as a scaffold for the conjugation of the electrochemical tag (in this specific case methylene blue) and of the thiol group for efficient attachment to a gold electrode surface was immobilized onto the surface of a gold electrode. The DNA nanoswitch is rationally designed to adopt a stem-loop conformation in the absence of the specific target antibody, thus supporting efficient electron transfer of the methylene blue redox molecule. The nanoswitch is also designed to have two tails to support hybridization of two DNA strands with two antigens conjugated at their ends so that the antigens are located in the middle of the two strands of the stem. Upon binding of the antibody to one of these antigens, the high effective concentration of the second antigen provides the driving force to open the switch and thus separate the reporter elements. This results in a decrease in the observed electrochemical signal that is proportional to the target antibody concentration. Because this is based on an electrochemical output, this sensor behaves well even in complex samples (i.e., whole blood), making it superior to similar optical approaches. ${ }^{122}$ A limitation of this approach is the effect of the nanoswitch's density on the electrode's surface that affects signaling.

DNA Scaffolds for Electrochemical Antibody Detection Based on Steric Hindrance. More recently, ValléeBélisle described a highly selective DNA-based electrochemical sensor in which the detection of large macromolecules is based on steric hindrance effects at the nanoscale. ${ }^{123}$ The sensing principle of the platform exploits the high specificity and selectivity of DNA hybridization. Specifically, the binding of a large macromolecule, such as an antibody, to a signaling DNA strand generates steric hindrance effects that limit the ability of this DNA to hybridize to a surface-attached complementary strand (Figure 5A). The authors demonstrated that the efficiency of this hybridization is inversely correlated with the size of the molecule attached to the signaling DNA strand
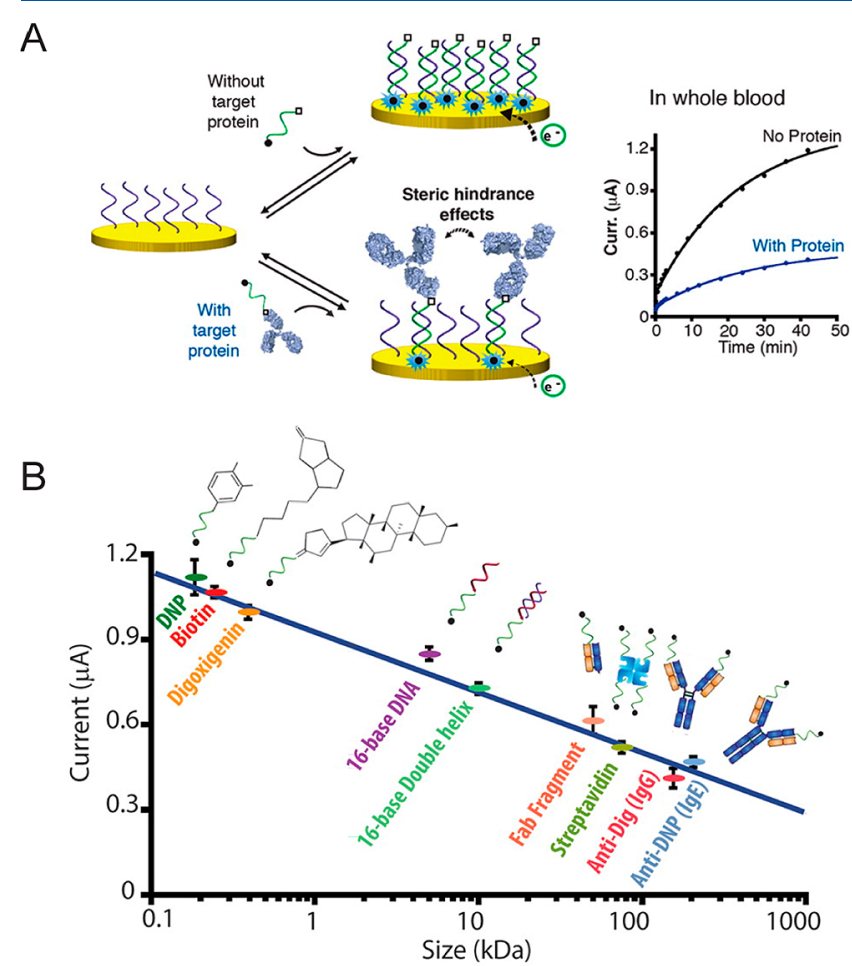

Figure 5. DNA-based sensors for electrochemical antibody detection. (A) DNA-based electrochemical sensor based on steric hindrance effects for the detection of large macromolecules. The electrochemical assay is composed of densely packed surface-bound capturing DNA strands (purple) and a free complementary signaling DNA strand (green) that is dually labeled with a small recognition element $(\square)$ and a signaling redox label $(\mathbf{O})$. In the presence of large target molecules, such as an antibody, the signaling strands are captured by the large macromolecules through binding of the recognition element, thus significantly limiting their ability to hybridize to the capturing strand on the electrode surface due to the steric hindrance effect. (B) The electrochemical signal measured is inversely correlated with the size of the molecule attached on the signaling strand. Reproduced from Mahshid, S. S.; Camiré, S.; Ricci, F.; Vallée-Bélisle, A. A highly selective electrochemical DNA-based sensor that employs steric hindrance effects to detect proteins directly in whole blood. J. Am. Chem. Soc. 2015, 137, 15596-15599 (ref 123). Copyright 2015 American Chemical Society. 


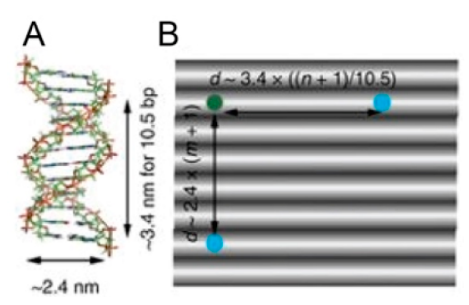

G
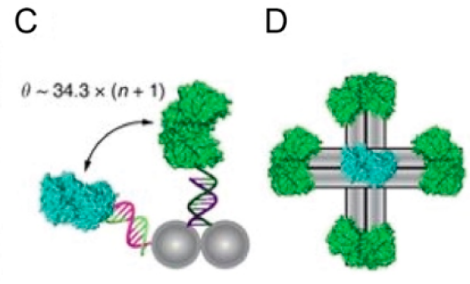
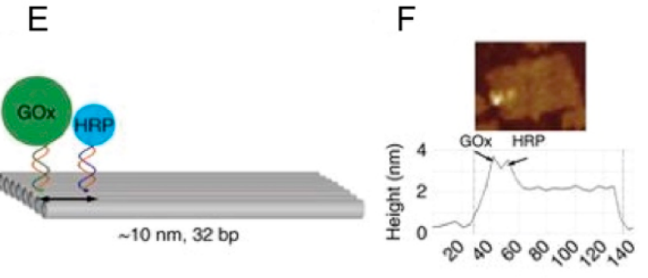

$(\mathrm{nm})$
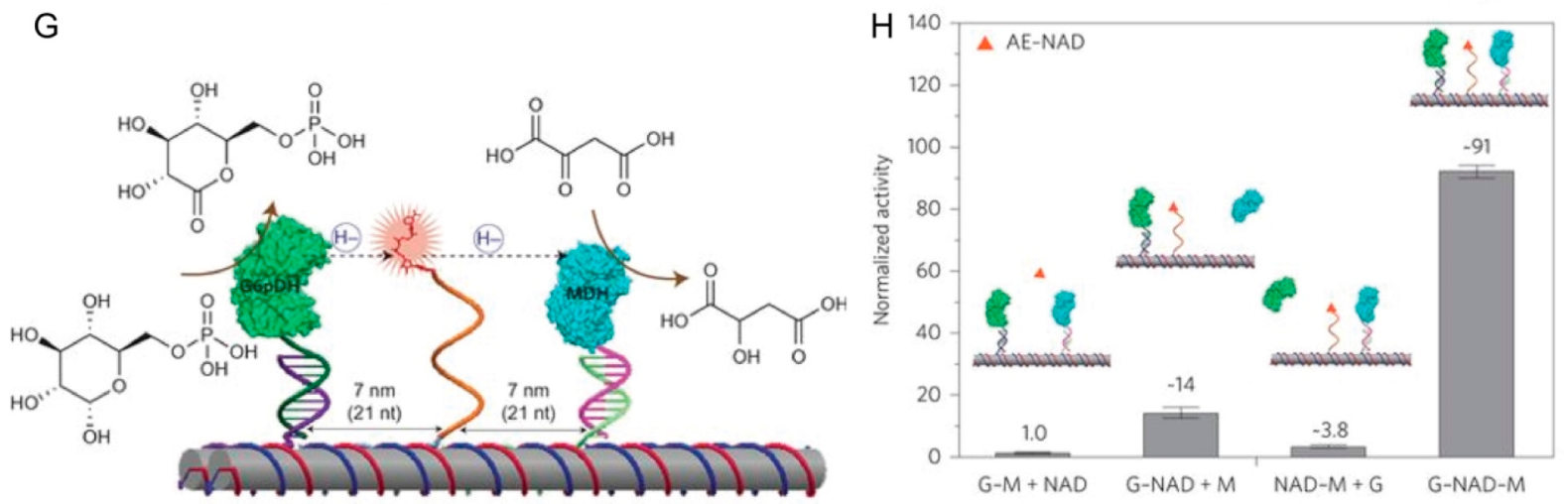

Figure 6. DNA-scaffolded enzymes. (A) DNA double-helix and (B) 2D DNA-based nanostructures. Controlling the position of anchored molecules in terms of (B) spacing distances, (C) relative angles, and (D) geometric arrangements. (E) Spatial organization of two enzymes (GOx and HRP) on a rectangular DNA origami tile with a $10 \mathrm{~nm}$ spacing distance. (F) AFM characterization of the enzyme-modified DNA nanostructure. The GOx-HRP assembly results in brighter spots due to the increased height. (G) Schematic of a two-enzyme/cofactor complex on a $2 \mathrm{D}$ origami scaffold. The $\mathrm{NAD}^{+}$-modified single-stranded $\mathrm{DNA}$ is positioned halfway between the two enzymes to facilitate the transfer of hydrides. $(\mathrm{H})$ Normalized cascade activities for the multienzyme assembly when one of the components is free in solution (G-M + NAD; G-NAD + M; NAD-M + G) compared to the fully assembled system (G-NAD-M). Reprinted by permission from Macmillan Publishers Ltd. Fu, J.; Yang, Y. R.; Johnson-Buck, A.; Liu, M.; Liu, Y.; Walter, N. G.; Woodbury, N. W.; Yan, H. Nat. Nanotechnol. 2014, 9, 531-536 (ref 127 ). Copyright 2014.

(Figure 5B). The platform enables the one-step quantitative detection of four different macromolecules (with sizes ranging from 50 to $150 \mathrm{kDa}$ ) with a low nanomolar detection limit within $10 \mathrm{~min}$ directly in whole blood. Moreover, the simultaneous detection of multiple antibodies directly was achieved by employing three electrodes, each functionalized with a specific capturing strand and used to simultaneously detect different antibodies. Given all these advantages, this novel, highly selective, steric hindrance-based assay could also be adapted in POC diagnostic sensors as well as into various formats such as fluorescent and surface plasmon resonancebased sensors.

Recently, the use of this platform has also been demonstrated for the detection of small molecules through a competitive assay directly in complex matrices. ${ }^{124}$ Specifically, the sensor comprises the capturing DNA strands, attached to the surface of a gold electrode, the complementary signaling DNA strand, which is dually labeled with the small analyte target (i.e., an antigen) and the redox moiety, and the specific antibody. In the absence of a competing antigen, the signaling strand is bound to the antibody and, due to the steric hindrance, this large conjugate is less able to bind the capturing strand, generating a weak electrochemical signal. Conversely, the presence of the free recognition element molecules competing for the same antibody allows the signaling strand to efficiently hybridize to most capturing strands, thus generating a large electrochemical current increase. To further increase the efficiency and the kinetics of DNA hybridization upon detection of the specific target antibodies, Kelley and Vallée-Bélisle proposed a similar approach employing nanostructured microelectrodes. ${ }^{125}$ As expected, detection sensitivity improved the morphology-induced blocking effects of the nanostructures on the electrode surface. Moreover, the effect of nanostructured microelectrodes enhanced the size-dependent hybridization rate of DNA complexes and, thus, the response time of the platform. For all of the features mentioned above, the deployment of nanostructured microelectrodes in this assay allows rapid time to answer, higher sensitivity, and lower detection limits for the detection of macromolecules compared to the properties of the previously developed platform.

\section{DNA NANOSTRUCTURES AS SCAFFOLDS FOR SENSING APPLICATIONS}

Multienzyme Complexes on Two-Dimensional (2D) and Three-Dimensional (3D) DNA Origami Scaffolds. The confinement of enzymes to minimal spatial environments, such as on biological membranes, organelles, and other nanoscale compartments, is a key component of controlling the complex network of chemical reactions within the cell. Inspired by nature, a number of strategies to confine enzymes in two- and three-dimensional DNA nanostructured scaffolds have been adopted to control the spatial coordinates and dynamic temporal actuation of enzymatic activity. DNAscaffolded enzymes have great potential for the generation of advanced active nanomaterials with application in fuel cells, biosensors, and drug delivery systems.

In 2014, the group of $\mathrm{H}$. Yan pioneered the design of multienzyme complexes on a 2D DNA nanostructure scaffold in which a DNA-based swinging arm allows for efficient hydride transfer between a two-enzyme cascade consisting of glucose-6-phosphate dehydrogenase and malic dehydrogenase (Figure 6). ${ }^{126,127}$ Before this demonstration, DNA-enzyme assemblies were used only to control cascades of enzymatic 
A

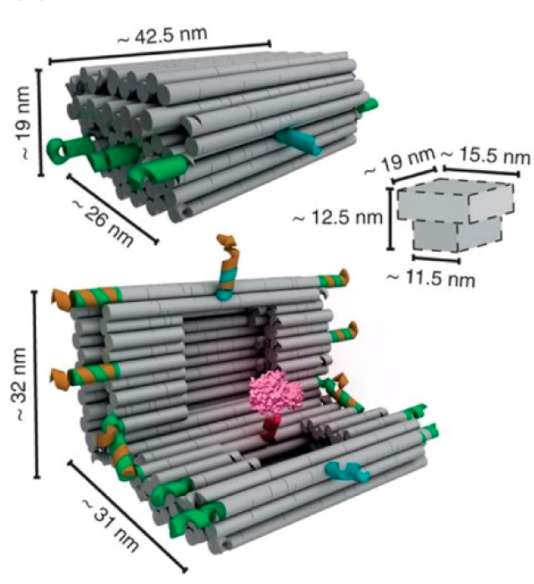

B
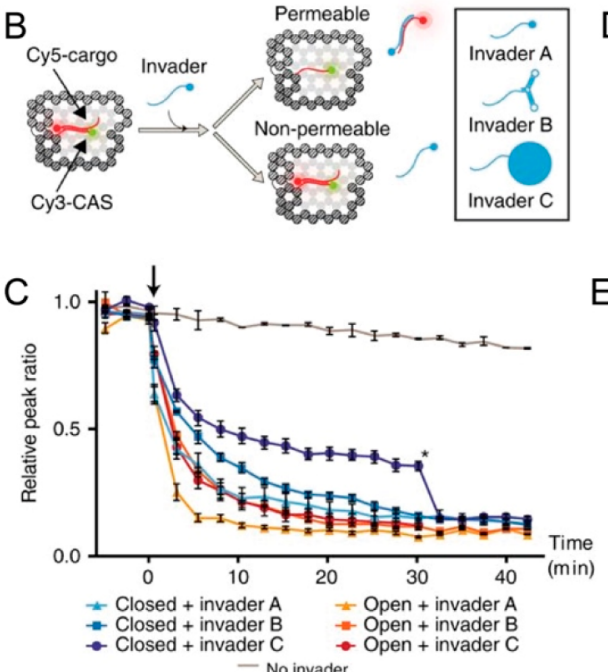

D

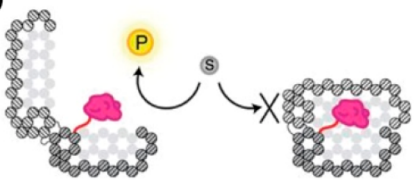

E

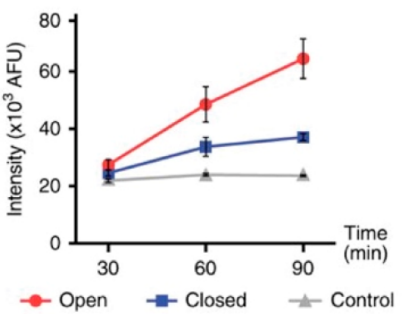

F

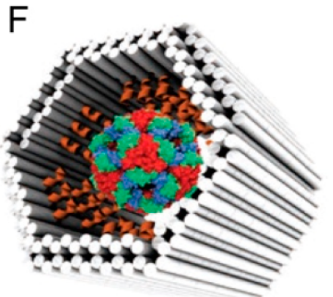

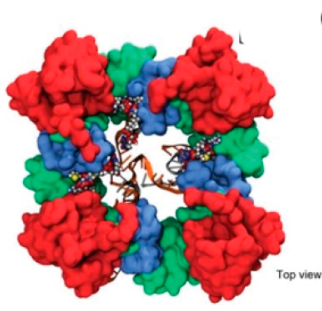

G

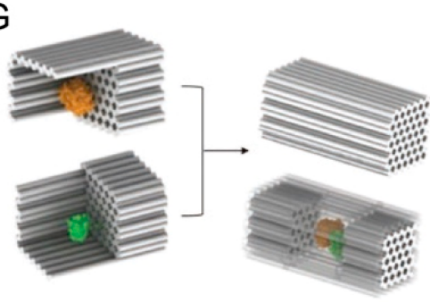

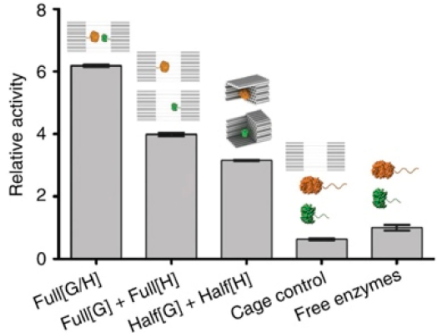

Figure 7. Enzyme complexes on 3D DNA origami scaffolds. (A) 3D rendering and size of the DNA nanocontainer in the closed and open states. (B and C) Controlling the permeability of the DNA nanostructure as a function of fluorescent DNA cargo release using DNA invaders of different sizes. The black arrow indicates addition of invaders. (D and E) Monitoring the proteolytic enzymatic activity in either closed and opened states. (F) Supramolecular protein encapsulation into a DNA hollow nanostructure. The encapsulated DegP protein in its monomeric form is constituted by three domains: protease (red), PDZ1 (green), and PDZ2 (blue) domains. (G) Schematic of the assembly and activities of a DNA nanocage encapsulating a pair of GOx (orange) and HRP (green) enzymes. Panels A-E reprinted by permission from Macmillan Publishers Ltd. Grossi, G.; Jepsen, M. D. E.; Kjems, J.; Andersen, E. S. Nat. Commun. 2017, 8, 992 (ref 147). Copyright 2017. Panels F and G reprinted by permission from Macmillan Publishers Ltd. Sprengel, A.; Lill, P.; Stegemann, P.; Bravo-Rodriguez, K.; Schöneweiß, E.; Merdanovic, M.; Gudnason, D.; Aznauryan, M.; Gamrad, L.; Barcikowski, S.; Sanchez-Garcia, E.; Birkedal, V.; Gatsogiannis, C.; Ehrmann, M.; Saccà, B. Nat. Commun. 2017, 8, 14472 (ref 148). Copyright 2017.

reactions by changing the relative distance and orientation of enzymatic elements. ${ }^{128-131}$ In this work, the authors demonstrated the ability to control both the position and the stoichiometry of a $\mathrm{NAD}^{+}$-modified DNA arm, together with the interenzyme distance on the DNA scaffold. By doing so, they showed an enhancement of the activity of the enzymatic cascade ( $\sim 90$-fold increase) compared to that of an enzyme system in the presence of freely diffusing $\mathrm{NAD}^{+}$. The selfassembly properties of DNA have also been employed to create 3D "plug-and-play" DNA nanoboxes capable of encapsulating enzymes. In 2016, Yan and co-workers were able to enclose active enzymes within a multilayered DNA nanobox, ${ }^{132}$ demonstrating an increased turnover number for both individual enzymes and co-localized enzyme cascades. The authors described the inverse correlation between the enzymatic activity enhancement and the size of the protein as a stabilizing effect of the negatively charged DNA surface on the active enzyme conformation. In this context, new studies suggested that these effects could be ascribed to an improved affinity of the substrate for the DNA template and to intermolecular interactions that often are enzyme- and DNA sequence-specific. $^{133,134}$

In fact, the mechanistic understanding of the enhancement of enzymatic activities on DNA nanostructures is still not clear, and this issue is attracting growing interest. The reported evidence was frequently ascribed to facilitated transport, or socalled substrate channeling, where a proximity effect between the coupled enzymes leads to a faster transfer of produced intermediate molecules that act as the substrate of the second enzyme. ${ }^{135-137}$ Taking a different approach, Zhang et al. examined the proximity effect using a GOx-HRP conjugate mediated by a small molecule linker without relying on DNA nanostructure. ${ }^{138}$ They placed two enzymes within $2 \mathrm{~nm}$ of each other and demonstrated that the catalytic activity of both enzymes is preserved without any enhancement of cascade or direct substrate transfer. Because the proximity effect was not observed, the authors indicated $\mathrm{pH}$ dependence as the source of activity enhancement observed by Yan and co-workers. Because of the many negative charges on large DNA structures, the $\mathrm{pH}$ close to the surface of a DNA origami experienced by enzymes is much lower $(1-1.5 \mathrm{pH}$ units) than that in the bulk solution because the protons are attracted to the negatively charged interface. According to evidence showing an increased maximal turnover rate of tested enzymes under more acidic conditions, the authors suggested that the origin of the improvement of enzymatic activities on a DNA scaffold is likely the microenvironment $\mathrm{pH}$ effects on the surface of the origami where enzymes operate. Although the question is still open to debate, ${ }^{139-141}$ consistent with these findings it is now 
well established that a DNA scaffold alters the enzyme characteristics and the local environment. ${ }^{142}$

In 2013, the group of Desideri demonstrated the first example of temperature-controlled encapsulation and release of the horseradish peroxidase enzyme (HRP) in a DNA cage. In this work, the authors show the encapsulation (closed conformation at $4{ }^{\circ} \mathrm{C}$ ) and release (open conformation at 37 ${ }^{\circ} \mathrm{C}$ ) of an enzyme cargo in a hairpin-modified octahedral nanocage. ${ }^{143,144}$ Recently, the same research group also investigated the selective mechanism of cellular uptake in cells of pristine DNA nanocages expressing low-density lipoprotein receptor-1 (LOX-1), a scavenger receptor associated with cardiovascular diseases. ${ }^{145}$ The stability of the nanostructure in the biological fluids and efficient internalization in vesicles expressing the specific receptor were demonstrated. Later, in $2017 \mathrm{Kim}$ and co-authors incorporated switchable domains on a tethraedral DNA cage to achieve stimulus-responsive opening and closing activity to control the protease-mediated degradation and binding affinity of the protein with the specific antibody counterpart. ${ }^{146}$

Recently, Andersen and co-workers also designed DNAbased nanocontainers with programmable structural and dynamic properties that can cage enzymes and control the interactions with their specific substrate. ${ }^{147}$ To do so, the authors designed a large and isolated cavity into a DNA origami device and loaded the enzyme in this structure (Figure 7), showing the ability of such DNA nanocages to protect the catalytic enzymatic activity from deactivation in the presence of proteases and to prevent enzyme aggregation under challenging biological conditions. This system represents the first example of an enzyme encapsulated within switchable DNA nanostructures capable of controlling its catalytic activity. The enzyme in fact can interact with free substrate molecules only when the DNA cage opens in response to specific molecular cues. Although this approach should allow a wide range of enzyme-substrate systems to be controlled as a function of a number of chemical cues, the low cargo loading due to unfavorable reaction conditions in the constrained cavity of the cage and the permeability of the DNA nanocontainer to freely diffusing molecules require further developments.

Saccà and co-authors also reported one of the largest DNAprotein complexes that is spatially controlled by supramolecular interactions through the decoration of the inner surface of a DNA origami nanostructure with multiple ligands that specifically interact with their corresponding binding sites on the protein surface with programmable symmetry (Figure $7 F)$. Results showed high specificity in the host-guest recognition mechanism and the capability of controlling protein release in the presence of a specific molecular cue. Because naturally occurring host-guest complexes generally rely on noncovalent interactions between complementary shapes, mimicking this approach provides a means of trapping the guest molecule (i.e., enzyme) in its native form and overcoming limitations concerning the chemistry of DNAprotein conjugation. However, it is important to note that this strategy is not easy to generalize to other enzymes and requires a highly specific molecular design of the nanocontainer. ${ }^{148}$

To further explore the advantages of enzymes immobilized on a nucleic acid scaffold compared to free, non-immobilized enzymes, Collins et al. developed a simple and robust method for the formation of a DNA-crowded enzyme complex using hybridization chain reaction. ${ }^{149}$ More recently, L. Zhou and his co-workers reported the formation of an enzyme cascade on DNA triangle prism nanostructures grafted onto microbeads. The resulting system is capable of performing efficient catalytic production of nitric oxide in the microreactor. ${ }^{150}$

The examples reported above indicate that the ordered colocalization, supramolecular assembly, and encapsulation of enzymes and/or cofactors into controlled 2D and 3D DNA nanostructures can dramatically enhance overall cascade catalysis, leading to higher selectivity and potentially improving the analytical performance, for instance, of next-generation enzyme-based electrochemical biosensors. In this regard, selfassembly properties of DNA nanostructures can lead to an easier and more efficient organization of enzyme cascade reactions on the surface of the electrode resulting in enhanced electrochemical features. ${ }^{151}$ Nevertheless, despite this progress and industrial interest to turn toward more advanced and efficient multistep enzyme-catalyzed processes, ${ }^{152}$ scaling up these DNA-organized enzyme cascade reactions to real analytical applications remains challenging.

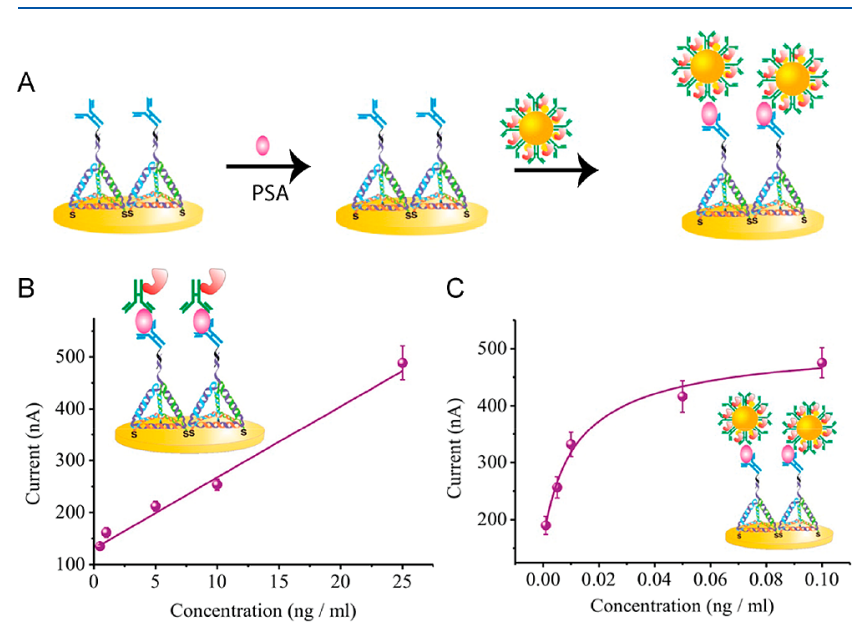

Figure 8. Tetrahedral DNA nanostructure as a scaffold of electrochemical platforms. (A) Protein detection (PSA) using a tetrahedral DNA scaffold. Antibodies are conjugated on TDNs and employed as a recognition probe for protein detection. This architecture displays improved affinity compared to that of antibody-modified singlestranded DNA probes anchored on the gold surface. (B) Linearity range of PSA detection using a sandwich type immunoassay. (C) Antibody-conjugated gold nanoparticles for highly sensitive electrochemical detection of PSA. Reproduced from Chen, X.; Zhou, G.; Song, P.; Wang, J.; Gao, J.; Lu, J.; Fan, C. H.; Zuo, X. Anal. Chem. 2014, 86, 7337-7342 (ref 160). Copyright 2014 American Chemical Society.

DNA Tetrahedral Scaffolds for Sensing Applications. Biosensing interfaces play a crucial role in the development of electrochemical biosensors because the binding of molecular target occurs at the interface between the surface where the responsive probe is immobilized and the bulk solution. Focusing on DNA-based biosensing interface, researchers have established that one of the main limitations in developing high-performance DNA sensors is the high heterogeneity of DNA immobilization on the surface. Fan and co-workers pioneered the use of tetrahedral DNA nanostructure (TDN) to overcome such a challenging limitation. The group of $\mathrm{C}$. Fan developed different TDN-based sensing platforms able to detect multiple-level biomarkers, including nucleic acid targets, proteins, and small molecules with potential for early 

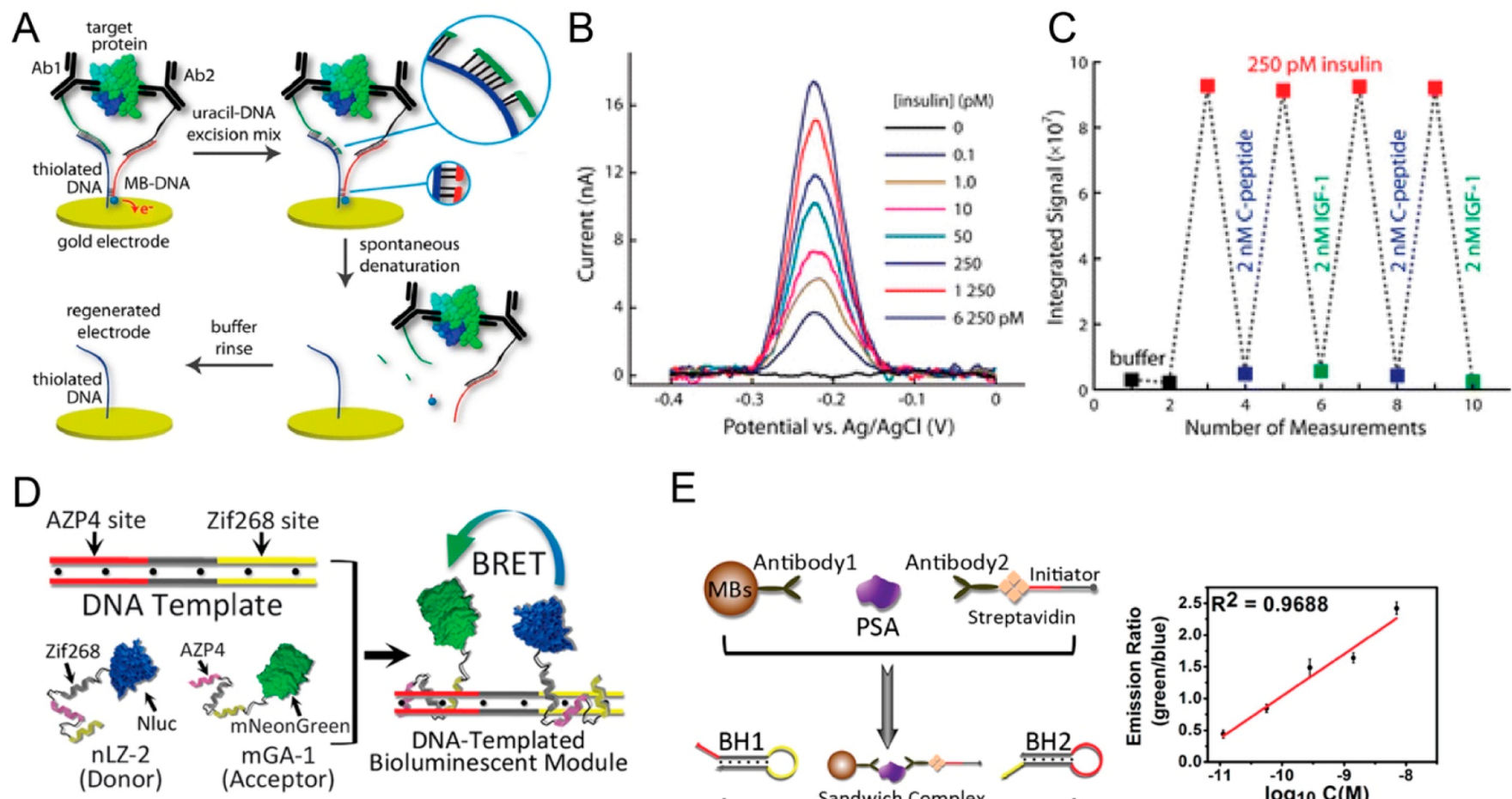

$\mathrm{E}$
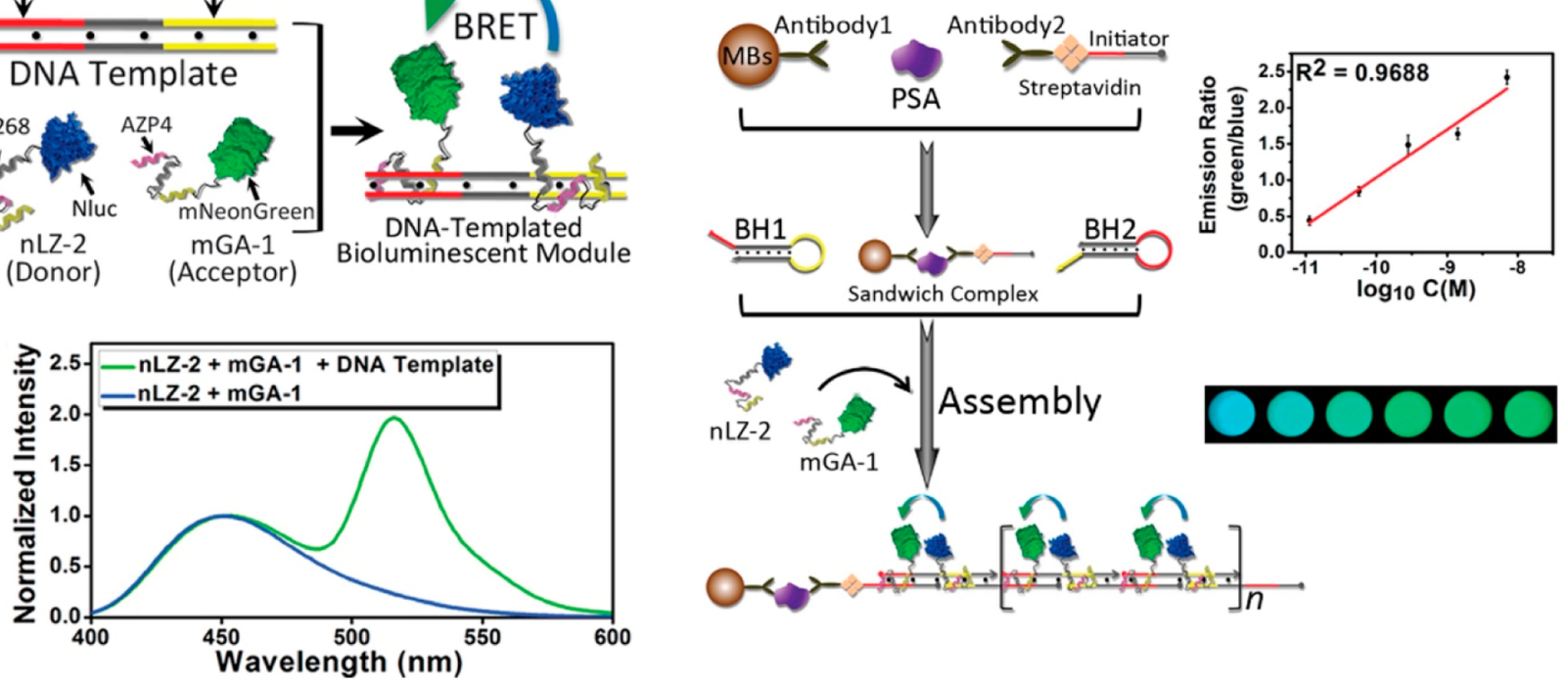

Figure 9. Proximity-based sensing platform using DNA as a scaffold. (A) Reusable electrochemical proximity-based platform for single-step detection of protein in biological matrices. (B) SWV scans for insulin quantitation in murine blood serum. (C) Specificity test by challenging the electrochemical sensor with proteins with a similar structure. Reproduced from Hu, J.; Yu, Y.; Brooks, J. C.; Godwin, L. A.; Somasundaram, S.; Torabinejad, F.; Kim, J.; Shannon, C.; Easley, C. J. J. Am. Chem. Soc. 2014, 136, 8467-8474 (ref 166). Copyright 2014 American Chemical Society. (D) Schematic representation of proximity-based DNA-templated bioluminescent energy transfer. (E) Amplified BRET assay for PSA using antibodies as affinity elements. Reproduced from Li, Y.; Yang, P.; Lei, N.; Ma, Y.; Ji, Y.; Zhu, C.; Wu, Y. Anal. Chem. 2018, 90, 11495-11502 (ref 169). Copyright 2017 American Chemical Society.

diagnostics and personalized medicine. ${ }^{153-158}$ DNA tetrahedra are a type of nucleic acid framework that can be easily produced using either tile or origami assembly and show many advantages compared for instance to self-assembled monolayers. First, TDNs can act as a discrete scaffold for site-specific chemical/biochemical functionalization of small molecules, antibodies, proteins, and nanoparticles either at the edges or in the cavity. Second, thiol-modified TDNs can be linked on the surface of a gold electrode with high reproducibility and stability over time. Finally, TDN-based sensing platforms improve the sensitivity of detection by several orders of magnitude because of the higher accessibility of the target to the probe. Hence, TDNs have been extensively characterized to design a number of DNA-based interfaces for a variety of sensing and in vivo applications. ${ }^{159}$

In 2014, Fan and co-workers tested a TDN-based sensing platform to site-specifically anchor DNA-conjugated antibodies via complementary DNA strands (Figure 8). This approach tackles one of the major problems in protein assays (ELISA, protein microarrays, etc.) represented by the physical adsorption or covalent conjugation of the biomolecular probe that does not support the proper orientation of the probe or reduce its overall activity. Hence, Fan and co-workers employed TDN-engineered interfaces to site-specifically anchor DNA-conjugated antibodies through binding with a complementary DNA bridge. On the basis of this new strategy, they measured an improvement of approximately 2-3 orders of magnitude for a variety of analytes compared to routine methodologies (i.e., tumor necrosis factor- $\alpha$, prostate-specific antigen, and $\alpha$-fetoprotein). ${ }^{160}$

Proximity-Based Assembly of DNA Scaffolds for Sensing Applications. As discussed above, one of the most explored natural strategies for controlling protein activity exploits co-localization and confinement in an extremely small volume, which results in an increase of their effective local concentration. This naturally occurring mechanism has been widely reproduced and exploited for sensing applications. Simultaneous binding of two nucleic acid-modified affinity ligands to a single target molecule can dramatically increase their local effective concentrations and trigger the assembly of 
A

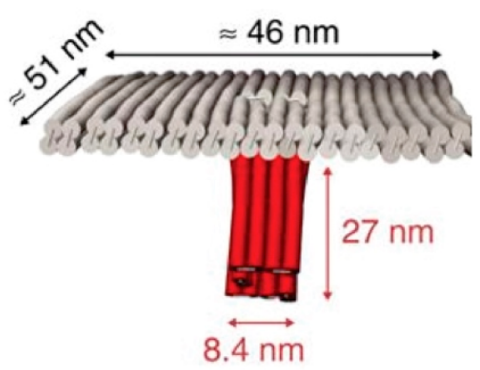

D

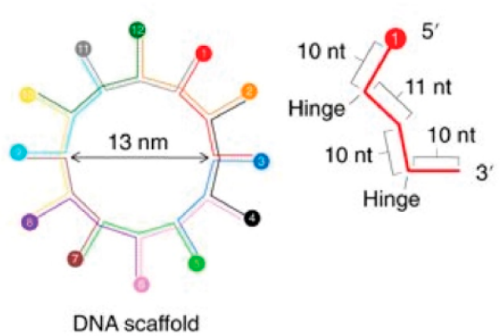

B
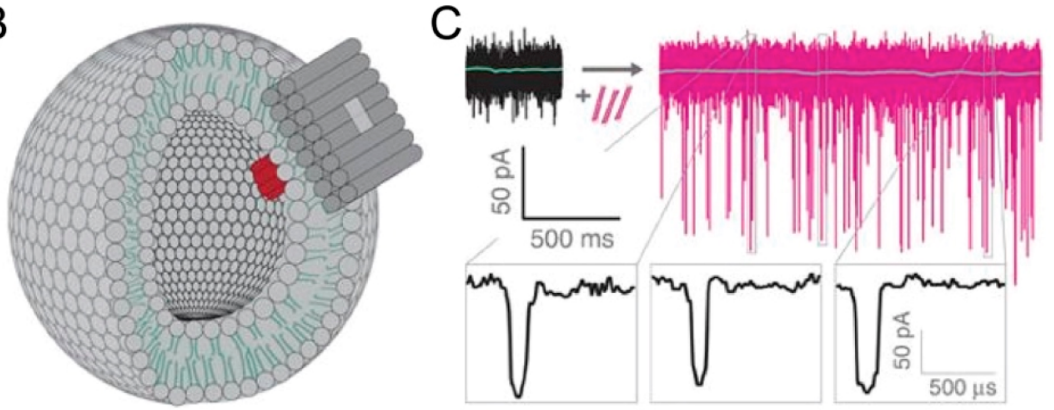

$E$

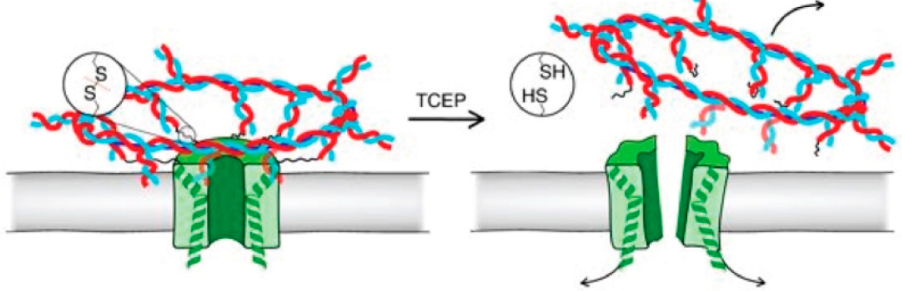

Figure 10. DNA scaffold for synthetic nanopores. (A) Design of a DNA-based T pore composed of a double-layered top plate and long stem spaning the membrane. (B) Schematic representation of a DNA-based pore interacting with small unilamellar vesicles. (C) Current signal generated in a single DNA channel bound to a lipid bilayer membrane in the presence and absence of target analytes. Reprinted by permission from Macmillan Publishers Ltd. Krishnan, S.; Ziegler, D.; Arnaut, V.; Martin, T. G.; Kapsner, K.; Henneberg, K.; Bausch, A. R.; Dietz, H.; Simmel, F. C. Nat. Commun. 2016, 7, 12787 (ref 171). Copyright 2016. (D) Schematic of a DNA scaffold that supports peptide nanopores. (E) The DNA scaffold can be displaced in the presence of a reducing agent. Reprinted by permission from Macmillan Publishers Ltd. Spruijt, E.; Tusk, S. E.; Bayley, H. Nat. Nanotechnol. 13, 739-745 (ref 172). Copyright 2018.

nucleic acid strands that would otherwise be impossible to achieve at low concentrations. A number of homogeneous and heterogeneous assays that exploit proximity-based bindinginduced DNA assembly have been developed for the detection of proteins, pathogens, and other molecules. Other reviews can give a more detailed overview of the efforts and development in the field. ${ }^{161-164}$ Here we focus only on recent works (fewer than five years old) that demonstrated single-step detection of target analytes through proximity-based DNA assembly without relying on any enzymatic amplification step (i.e., qPCR).

In 2015, the Sodemberg group engineered a method (proxHCR) that allows the sensitive detection of interacting proteins through the combination of proximal binding with hybridization chain reaction (HCR) for signal amplification. ${ }^{165}$ Specifically, they employed oligonucleotide hairpin probes conjugated to antibodies that come into the proximity of each other after target protein detection. This triggers a chain reaction of hybridization that results in an amplified fluorescent output. To demonstrate the feasibility of this sensing system, they performed in situ analysis of post-translational modifications (PTMs) and protein-protein interactions (PPIs) using different cell lines and flow cytometric analysis. Although the approach is interesting and less expensive compared to the classic proximity ligation assay, the design of the system is complicated and the protein detection still requires the introduction of a single-stranded DNA initiator and multiple recognition events, thus limiting its applicability in bodily fluids or in tissue sections.

$\mathrm{Hu}$ et al. reported an electrochemical proximity assay for the real-time and single-step quantification of protein in the low picomolar range of concentration in complex matrices. Square wave voltammetry measurements require $<5 \mathrm{~min}$, and calibration over different electrodes was demonstrated to be robust (Figure 9A-C). ${ }^{166}$ The sensor can be regenerated enzymatically up to 20 times on a single gold electrode. Wen et al. also proposed a similar approach based on photoelectrochemical detection on an $\mathrm{ITO} / \mathrm{TiO}_{2} / \mathrm{CdS}$ electrode for the monitoring of insulin, displaying a linear range from 10 $\mathrm{fM}$ to $10 \mathrm{nM}$ and a detection limit of $3.0 \mathrm{fM}$ without the need for a washing step. $^{167}$ Furthermore, proximity-dependent complementation of DNAzyme has also been successfully tested to generate a chemiluminescence-based (CL) imaging method for the rapid and high-throughput detection of protein targets in bioanalysis. ${ }^{168}$ Most of these examples reported above take advantage of the use of a DNA-antibody conjugate, but efficient chemical methods for producing high-quality conjugates from commercially available antibodies are still lacking. This problem often results in nonspecifically labeled antibodies showing off-target binding and rapid clearance for in vivo applications. ${ }^{70}$

More recently, Y. Li et al. developed a modular strategy for amplified BRET detection of protein biomarkers in human peripheral blood samples triggered by the simultaneous colocalization of NanoLuc luciferase (Nluc) and mNeonGreen as luminescent proteins fused with specific zinc finger domains (Figure 9D-E). BRET-based assays have many advantages compared, for instance, to classic fluorescent systems. First, the signal emission is independent of external excitation sources and exploits only the light emitted by enzymatic luciferase activity as internal excitation energy. Second, emissions of light from both the donor and the acceptor can be used for ratiometric quantification of target analytes. Here the authors designed a proximity-based DNA-templated bioluminescent method in which efficient energy transfer between two emitting proteins acting as an energy donor (luciferase) and an energy acceptor (green fluorescent protein, GFP) provides a means of measuring prostate-specific antigen (PSA) with the 
detection limit in the picomolar range using a smartphone camera. The proposed sensing platform takes advantage of the co-localization of both luminescent signaling modules to the same amplified DNA resulting from the HCR amplification circuit. ${ }^{169}$ Although BRET-based assays appear as powerful tools for sensing, imaging, and biological applications, luminescent proteins emitting at different wavelengths showing similar performance of luciferase are necessary to move forward multicolor imaging of multiple analytes. ${ }^{170}$

DNA Scaffolds for Creating Synthetic Nanopores for Single-Molecule Biosensing. The construction of stable and versatile scaffolds is an important nanotechnology goal for the development of functional membrane-spanning nanopores with a wide range of potential single-molecule label-free biosensor applications such as DNA and protein sensing or the characterization of protein-DNA and protein-protein interactions. However, this is generally complicated by complex requirements for the structure and assembly of both the scaffold and the nanopore. In 2016, the group of F. Simmel designed a large DNA-based membrane channel that can penetrate lipid bilayer membranes. This DNA nanopore (inner dimensions of $\sim 4 \mathrm{~nm} \times 4 \mathrm{~nm}$ ) allows for electrically driven single- and double-stranded DNA translocation and sensing, showing good Ohmic conductance values $(G \sim 3 \mathrm{nS})$ in accordance with its dimensions (Figure 10A-C). Nevertheless, a number of limitations are still present such as the availability of a sufficient number of membrane-anchoring positions and the dimensions of the origami scaffold length. ${ }^{171}$

Recently, Spruijt et al. demonstrated the first example of organized DNA nanostructures able to promote the assembly of peptides onto nanopores. ${ }^{172}$ Using this approach, they demonstrated the organization of nanopores of different dimensions and pore sizes. Specifically, they highlighted that DNA rings are able to template the spatial organization of amphiphilic $\alpha$-helical Wza peptides to form uniform nanopores in planar lipid bilayers(Figure 10D-E). Interestingly, Wza peptides show conductive properties only when assembled on the DNA nanostructured scaffold, whereas a rapid disruption of the nanopores from the lipid bilayer is observed by removing the DNA scaffold through the cleavage of the linkers. This evidence clearly demonstrates the essential role of the scaffolded DNA nanostructure in their stability. HenningKnechtel et al. also showed functional hybrid nanopores employing DNA-peptide chimera probes that bring $\alpha$ hemolysin $(\alpha \mathrm{HL})$ monomers on well-defined DNA nanostructures into artificial pores. ${ }^{173}$

Despite these relevant innovations, different limitations still have to be addressed to translate this technology to work in complex media. First, the potential DNA degradation over time in living cells that could require the use of a synthetic nucleic acid-mimicking strand. Second, the undesirable ion permeability due to DNA duplex flexibility and consequent uncontrolled gating is still limiting the sensitivity of the systems. Overcoming these limitations could open a wide range of possibilities, from the detection of proteins in complex mixtures to the mapping of epigenetic markers on doublestranded DNA sequences.

\section{CONCLUSIONS}

DNA nanotechnology allows the rational design of functional nanostructures and devices. A nearly infinite number of sequences able to bind reliably to their complementary partners can be used to create $2 \mathrm{D}$ and $3 \mathrm{D}$ nanostructures with different shapes and functionalities. Taking advantage of the predictability of DNA interactions and recent progress in the conjugation of DNA sequences with biomolecules and small molecules, we are now able to finely control the spatial organization of responsive molecular components into a DNAbased nanostructure or nanodevice acting as a scaffold. Here we showed a number of programmable DNA scaffold systems with different levels of complexity (2D DNA nanostructures, DNA origami, tetrahedral DNA, beacons, etc.) employed to organize different molecules (i.e., enzymes, antigens, and peptides) with nanometer precision and generate analytical tools and control reactions with potential sensing and drug delivery applications.

\section{AUTHOR INFORMATION}

\section{Corresponding Authors}

*E-mail: alessandro.porchetta@uniroma2.it.

*E-mail: francesco.ricci@uniroma2.it.

ORCID $\odot$

Alessandro Porchetta: 0000-0002-4061-5574

Francesco Ricci: 0000-0003-4941-8646

\section{Notes}

The authors declare no competing financial interest.

\section{Biographies}

Simona Ranallo is a postdoctoral researcher in the Department of Chemistry of the University of Rome Tor Vergata. During her Ph.D. study, her research interests focused on the development of novel DNA-based switching systems controlled by antibodies and other macromolecular targets for diagnostic and drug release applications. At the moment, she is studying the possibility of employing antibodies as a triggering input to control the formation of DNA-based nanostructures.

Alessandro Porchetta is a senior researcher in the Department of Chemistry of the University of Rome Tor Vergata. During his Ph.D. study, his research activities mainly focused on the development of innovative strategies for re-creating naturally occurring mechanisms to both narrow and broaden the dynamic range of structure-switching DNA-based receptors for sensing applications. At the moment, he is exploring the possibility of using DNA-based nanodevices for diagnostic and drug monitoring applications.

Francesco Ricci is an associate professor in the Department of Chemistry of the University of Rome Tor Vergata. His research interests include functional DNA nanotechnology, biosensing, and synthetic biology. He was awarded an ERC Starting Grant (2013), an ERC Consolidator Grant (2018) the inaugural ACS Advances in Measurement Science Lectureship Award (2017), and the Heinrich Emanuel Merck Award for Analytical Science (2017).

\section{ACKNOWLEDGMENTS}

This work was supported by the Italian Ministry of University and Research (MIUR) through the project PRIN, by Associazione Italiana per la Ricerca sul Cancro, AIRC (Project n. 14420) (F.R.), and by the European Research Council (ERC) (Project n. 336493) (F.R.).

\section{REFERENCES}

(1) Kogikoski, S., Jr.; Paschoalino, W. J.; Kubota, L. T. TrAC, Trends Anal. Chem. 2018, 108, 88-97.

(2) Chen, Y.-J.; Groves, B.; Muscat, R. A.; Seelig, G. Nat. Nanotechnol. 2015, 10, 748-760.

(3) Keyser, U. F. Nat. Nanotechnol. 2016, 11, 106-108. 
(4) Du, Y.; Dong, S. Anal. Chem. 2017, 89, 189-215.

(5) Rossetti, M.; Porchetta, A. Anal. Chim. Acta 2018, 1012, 30-41.

(6) Zhang, P.; Jiang, J.; Yuan, R.; Zhuo, Y.; Chai, Y. J. Am. Chem. Soc. 2018, 140, 9361-9364.

(7) Liu, M.; Zhang, Q.; Li, Z.; Gu, J.; Brennan, J. D.; Li, Y. Nat. Commun. 2016, 7, 12074.

(8) Li, J.; Green, A. A.; Yan, H.; Fan, C. Nat. Chem. 2017, 9, 10561067.

(9) Zadegan, R. M.; Jepsen, M. D. E.; Hildebrandt, L. L.; Birkedal, V.; Kjems, J. Small 2015, 11, 1811-1817.

(10) Genot, A. J.; Baccouche, A.; Sieskind, R.; Aubert-Kato, N.; Bredeche, N.; Bartolo, J. F.; Taly, V.; Fujii, T.; Rondelez, Y. Nat. Chem. 2016, 8, 760-767.

(11) Kopperger, E.; List, J.; Madhira, S.; Rothfischer, F.; Lamb, D. C.; Simmel, F. C. Science 2018, 359, 296-301.

(12) Jung, C.; Allen, P. B.; Ellington, A. D. Nat. Nanotechnol. 2016, 11, 157-163.

(13) Yue, L.; Wang, S.; Lilienthal, S.; Wulf, V.; Remacle, F.; Levine, R. D.; Willner, I. J. Am. Chem. Soc. 2018, 140, 8721-8731.

(14) Yang, Y.; Lin, C. Science 2017, 357, 352-353.

(15) Zhou, Z.; Yue, L.; Wang, S.; Lehn, J.-M.; Willner, I. J. Am. Chem. Soc. 2018, 140, 12077-12089.

(16) García-Fernández, A.; Megens, R. P.; Villarino, L.; Roelfes, G. J. Am. Chem. Soc. 2016, 138, 16308-16314.

(17) Seeman, N. C.; Sleiman, H. F. Nat. Rev. Mater. 2017, 3, 17068.

(18) Jones, M. R.; Seeman, N. C.; Mirkin, C. A. Science 2015, 347, 1260901.

(19) Lu, C.-H.; Cecconello, A.; Willner, I. J. Am. Chem. Soc. 2016, $138,5172-5185$.

(20) Hong, F.; Zhang, F.; Liu, Y.; Yan, H. Chem. Rev. 2017, 117, 12584-12640.

(21) (a) Wagenbauer, K. F.; Sigl, C.; Dietz, H. Nature 2017, 552, 78-83. (b) Gerling, T.; Wagenbauer, K. F.; Neuner, A. M.; Dietz, H. Science 2015, 347, 1446-1452.

(22) Chidchob, P.; Sleiman, H. F. Curr. Opin. Chem. Biol. 2018, 46, 63-70.

(23) Huggett, J. F.; Cowen, S.; Foy, C. A. Clin. Chem. 2015, 61, 7988.

(24) Petralia, S.; Conoci, S. ACS Sensors 2017, 2, 876-891.

(25) Lieberman, J. Nat. Struct. Mol. Biol. 2018, 25, 357-364.

(26) Mokhtarzadeh, A.; Tabarzad, M.; Ranjbari, J.; de la Guardia, M.; Hejazi, M.; Ramezani, M. TrAC, Trends Anal. Chem. 2016, 82, 316-327.

(27) Li, F.; Zhang, H.; Wang, Z.; Newbigging, A. M.; Reid, M. S.; Li, X.-F.; Le, X. C. Anal. Chem. 2015, 87, 274-292.

(28) Hasanzadeh, M.; Shadjou, N.; de la Guardia, M. TrAC, Trends Anal. Chem. 2017, 89, 119-132.

(29) Schoukroun-Barnes, L. R.; Macazo, F. C.; Gutierrez, B.; Lottermoser, J.; Liu, J.; White, R. J. Annu. Rev. Anal. Chem. 2016, 9, $163-181$.

(30) Lao, Y.-H.; Phua, K. K. L.; Leong, K. W. ACS Nano 2015, 9, $2235-2254$

(31) Chen, C.; Zhou, S.; Cai, Y.; Tang, F. npj Precision Oncology 2017, 1, 37.

(32) Ma, H.; Liu, J.; Ali, M. M.; Mahmood, M. A. I.; Labanieh, L.; Lu, M.; Iqbal, S. M.; Zhang, Q.; Zhao, W.; Wan, Y. Chem. Soc. Rev. 2015, 44, 1240-1256.

(33) Lyu, Y.; Chen, G.; Shangguan, D.; Zhang, L.; Wan, S.; Wu, Y.; Zhang, H.; Duan, L.; Liu, C.; You, M.; Wang, J.; Tan, W. Theranostics 2016, 6, 1440-1452.

(34) Quang, N. N.; Miodek, A.; Cibiel, A.; Duconge, F. Methods Mol. Biol. 2017, 1575, 253-272.

(35) Pang, X.; Cui, C.; Wan, S.; Jiang, Y.; Zhang, L.; Xia, L.; Li, L.; Li, X.; Tan, W. Cancers 2018, 10, 47.

(36) Porchetta, A.; Vallée-Bélisle, A.; Plaxco, K. W.; Ricci, F. J. Am. Chem. Soc. 2013, 135, 13238-13241.

(37) Lee, J.; Han, M. S.; Mirkin, C. A. Angew. Chem., Int. Ed. 2007, 46, 4093-4096.
(38) Li, D.; Wieckowska, A.; Willner, I. Angew. Chem., Int. Ed. 2008, 47, 3927-3931.

(39) Rana, M.; Balcioglu, M.; Robertson, N. M.; Hizir, M. S.; Yumak, S.; Yigit, M. V. Chem. Sci. 2017, 8, 1200-1208.

(40) Shimron, S.; Elbaz, J.; Henning, A.; Willner, I. Chem. Commun. 2010, 46, 3250-3252.

(41) Zhou, W.; Saran, R.; Liu, J. Chem. Rev. 2017, 117, 8272-8325.

(42) Halder, S.; Krishnan, Y. Nanoscale 2015, 7, 10008-10012.

(43) Huang, J.; Ying, L.; Yang, X.; Yang, Y.; Quan, K.; Wang, H.; Xie, N.; Ou, M.; Zhou, Q.; Wang, K. Anal. Chem. 2015, 87, 87248731.

(44) Zhou, J.; Amrane, S.; Korkut, D. N.; Bourdoncle, A.; He, H. Z.; Ma, D. L.; Mergny, J. L. Angew. Chem., Int. Ed. 2013, 52, 7742-7746.

(45) Ma, W.; Yan, L.; He, X.; Qing, T.; Lei, Y.; Qiao, Z.; He, D.; Huang, K.; Wang, K. Anal. Chem. 2018, 90, 1889-1896.

(46) Lannes, L.; Halder, S.; Krishnan, Y.; Schwalbe, H. ChemBioChem 2015, 16, 1647-1656.

(47) Hu, Y.; Ren, J.; Lu, C. H.; Willner, I. Nano Lett. 2016, 16, 4590-4594.

(48) Shi, L.; Peng, P.; Du, Y.; Li, T. Nucleic Acids Res. 2017, 45, $4306-4314$.

(49) Lei, Y.; He, X.; Tang, J.; Shi, H.; He, D.; Yan, L.; Liu, J.; Zeng, Y.; Wang, K. Chem. Commun. 2018, 54, 10288-10291.

(50) Li, T.; Famulok, M. J. Am. Chem. Soc. 2013, 135, 1593-1599.

(51) Qi, H.; Yue, S.; Bi, S.; Ding, C.; Song, W. Chem. Commun. 2018, 54, 8498-8501.

(52) Iacovelli, F.; Idili, A.; Benincasa, A.; Mariottini, D.; Ottaviani, A.; Falconi, M.; Ricci, F.; Desideri, A. J. Am. Chem. Soc. 2017, 139, $5321-5329$

(53) Yang, M.; Zhang, X.; Liu, H.; Kang, H.; Zhu, Z.; Yang, W.; Tan, W. Anal. Chem. 2015, 87, 5854-5859.

(54) Wu, N.; Willner, I. Nano Lett. 2016, 16, 6650-6655.

(55) Hu, Y.; Cecconello, A.; Idili, A.; Ricci, F.; Willner, I. Angew. Chem., Int. Ed. 2017, 56, 15210-15233.

(56) Liu, L.; Dou, C.; Liu, J.; Wang, X.; Ying, Z.; Jiang, J. Anal. Chem. 2018, 90, 11198-11202.

(57) Hu, Y.; Ren, J.; Lu, C.; Willner, I. Nano Lett. 2016, 16, 45904594.

(58) Idili, A.; Vallée-Bélisle, A.; Ricci, F. J. Am. Chem. Soc. 2014, 136, $5836-5839$.

(59) Zhang, Y.; Ma, F.; Tang, B.; Zhang, C.-Y. Chem. Commun. 2016, 52, 4739-4748.

(60) Li, C.; Tao, Y.; Yang, Y.; Xiang, Y.; Li, G. Anal. Chem. 2017, 89, 5003-5007.

(61) Vallée-Bélisle, A.; Bonham, A. J.; Reich, N. O.; Ricci, F.; Plaxco, K. W. J. Am. Chem. Soc. 2011, 133, 13836-13839.

(62) Adornetto, G.; Porchetta, A.; Palleschi, G.; Plaxco, K. W.; Ricci, F. Chem. Sci. 2015, 6, 3692-3696.

(63) Bertucci, A.; Guo, J.; Oppmann, N.; Glab, A.; Ricci, F.; Caruso, F.; Cavalieri, F. Nanoscale 2018, 10, 2034-2044.

(64) Du, Y.; Dong, S. Anal. Chem. 2017, 89, 189-215.

(65) Zhang, H.; Li, F.; Dever, B.; Li, X.-F.; Le, X. C. Chem. Rev. 2013, 113, 2812-2841.

(66) Ferapontova, E. E. Annu. Rev. Anal. Chem. 2018, 11, 197-218.

(67) Fojta, M.; Daňhel, A.; Havran, L.; Vyskočil, V. TrAC, Trends Anal. Chem. 2016, 79, 160-167.

(68) Evtugyn, G.; Hianik, T. TrAC, Trends Anal. Chem. 2016, 79, $168-178$.

(69) Yang, Y. R.; Liu, Y.; Yan, H. Bioconjugate Chem. 2015, 26, $1381-1395$

(70) Trads, J. B.; Tørring, T.; Gothelf, K. V. Acc. Chem. Res. 2017, 50, 1367-1374.

(71) Tsai, C.-T.; Robinson, P. V.; de Jesus Cortez, F.; Elma, M. L. B.; Seftel, D.; Pourmandi, N.; Pandori, M. W.; Bertozzi, C. R. Proc. Natl. Acad. Sci. U. S. A. 2018, 115, 1250-1255.

(72) Topalian, S. L.; Taube, J. M.; Anders, R. A.; Pardoll, D. M. Nat. Rev. Cancer 2016, 16, 275-287.

(73) Gopinath, S. C. B.; Tang, T.-H.; Citartan, M.; Chen, Y.; Lakshmipriya, T. Biosens. Bioelectron. 2014, 57, 292-302. 
(74) Shen, J.; Li, Y.; Gu, H.; Xia, F.; Zuo, X. Chem. Rev. 2014, 114, 7631-7677.

(75) Wen, W.; Yan, X.; Zhu, C.; Du, D.; Lin, Y. Anal. Chem. 2017, $89,138-156$.

(76) Mauriz, E.; García-Fernández, M. C.; Lechuga, L. M. TrAC, Trends Anal. Chem. 2016, 79, 191-198.

(77) Ricci, F.; Adornetto, G.; Palleschi, G. Electrochim. Acta 2012, $84,74-83$.

(78) Sharma, S.; Zapatero-Rodríguez, J.; Estrela, P.; O’Kennedy, R. Biosensors 2015, 5, 577-601.

(79) Nayak, S.; Blumenfeld, N. R.; Laksanasopin, T.; Sia, S. K. Anal. Chem. 2017, 89, 102-123.

(80) Khalil, D. N.; Smith, E. L.; Brentjens, R. J.; Wolchok, J. D. Nat. Rev. Clin. Oncol. 2016, 13, 273-290.

(81) Weichselbaum, R. R.; Liang, H.; Deng, L.; Fu, Y.-X. Nat. Rev. Clin. Oncol. 2017, 14, 365-379.

(82) Gotwals, P.; Cameron, S.; Cipolletta, D.; Cremasco, V.; Crystal, A.; Hewes, B.; Mueller, B.; Quaratino, S.; Sabatos-Peyton, C.; Petruzzelli, L.; Engelman, J. A.; Dranoff, G. Nat. Rev. Cancer 2017, 17, 286-301.

(83) Ecker, D. M.; Jones, S. D.; Levine, H. L. MAbs 2015, 7, 9-14.

(84) Krishnamurthy, A.; Jimeno, A. Pharmacol. Ther. 2018, 185, $122-134$.

(85) Dahlén, E.; Veitonmäki, N.; Norlén, P. Ther. Adv. Vaccines Immunother. 2018, 6, 3-17.

(86) Melero, I.; Sznol, M.; Tessmer, M. S.; Whiteside, T. L.; Wolchok, J. D. Clin. Cancer Res. 2018, 24, 1773-1774.

(87) Manson, G.; Houot, R. Ann. Oncol. 2018, 29, 588-601.

(88) Hartshorn, C. M.; Bradbury, M. S.; Lanza, G. M.; Nel, A. E.;

Rao, J.; Wang, A. Z.; Wiesner, U. B.; Yang, L.; Grodzinski, P. ACS Nano 2018, 12, 24-43.

(89) Ranallo, S.; Rossetti, M.; Plaxco, K. W.; Vallée-Bélisle, A.; Ricci, F. Angew. Chem., Int. Ed. 2015, 54, 13214-13218.

(90) Vallée-Bélisle, A.; Ricci, F.; Plaxco, K. W. Proc. Natl. Acad. Sci. U. S. A. 2009, 106, 13802-13807.

(91) Ricci, F.; Vallée-Bélisle, A.; Simon, A. J.; Porchetta, A.; Plaxco, K. W. Acc. Chem. Res. 2016, 49, 1884-1892.

(92) De Kosky, B. J.; Lungu, O. I.; Park, D.; Johnson, E. L.; Charab, W.; Chrysostomou, C.; Kuroda, D.; Ellington, A. D.; Ippolito, G. C.; Gray, J. J.; Georgiou, G. Proc. Natl. Acad. Sci. U. S. A. 2016, 113, E2636-E2645.

(93) Sela-Culang, I.; Kunik, V.; Ofran, Y. Front. Immunol. 2013, 4, 302.

(94) McCreery, T. Mol. Biotechnol. 1997, 7, 121-124.

(95) Eshhar, Z.; Ofarim, M.; Waks, T. J. J. Immunol. 1980, 124, $775-780$.

(96) White, R. J.; Kallewaard, H. M.; Hsieh, W.; Patterson, A. S.; Kasehagen, J. B.; Cash, K. J.; Uzawa, T.; Soh, H. T.; Plaxco, K. W. Anal. Chem. 2012, 84, 1098-1103.

(97) Banala, S.; Aper, S. J. A.; Schalk, W.; Merkx, M. ACS Chem. Biol. 2013, 8, 2127-2132.

(98) Porchetta, A.; Ippodrino, R.; Marini, B.; Caruso, A.; Caccuri, F.; Ricci, F. J. Am. Chem. Soc. 2018, 140, 947-953.

(99) Zhang, H.; Li, F.; Dever, B.; Wang, C.; Li, X.-F.; Le, X. C. Angew. Chem., Int. Ed. 2013, 52, 10698-10705.

(100) Rossetti, M.; Ippodrino, R.; Marini, B.; Palleschi, G.; Porchetta, A. Anal. Chem. 2018, 90, 8196-8201.

(101) Bertucci, A.; Porchetta, A.; Ricci, F. Anal. Chem. 2018, 90, $1049-1053$.

(102) Paige, J. S.; Wu, K. Y.; Jaffrey, S. R. Science 2011, 333, 642646.

(103) Hansen-Bruhn, M.; Nielsen, L. D. F.; Gothelf, K. V. ACS Sensors 2018, 3, 1706-1711.

(104) Zhang, Z.; Hejesen, C.; Kjelstrup, M. B.; Birkedal, V.; Gothelf, K. V. J. Am. Chem. Soc. 2014, 136, 11115-11120.

(105) Banala, S.; Arts, R.; Aper, S. J. A.; Merkx, M. Org. Biomol. Chem. 2013, 11, 7642-7649.

(106) Arts, R.; Den Hartog, I.; Zijlema, S. E.; Thijssen, V.; Van Der Beelen, S. H. E.; Merkx, M. Anal. Chem. 2016, 88, 4525-4532.
(107) Arts, R.; Ludwig, S. K. J.; Van Gerven, B. C. B.; Estirado, E. M.; Milroy, L.-G.; Merkx, M. ACS Sensors 2017, 2, 1730-1736.

(108) Golynskiy, M. V.; Rurup, W. F.; Merkx, M. ChemBioChem 2010, 11, 2264-2267.

(109) Janssen, B. M. G.; Lempens, E. H. M.; Olijve, L. L. C.; Voets, I. K.; van Dongen, J. L. J.; de Greef, T. F. A.; Merkx, M. Chem. Sci. 2013, 4, 1442-1450.

(110) Janssen, B. M. G.; Van Rosmalen, M.; Van Beek, L.; Merkx, M. Angew. Chem., Int. Ed. 2015, 54, 2530-2533.

(111) Engelen, W.; Meijer, L. H. H.; Somers, B.; De Greef, T. F. A.; Merkx, M. Nat. Commun. 2017, 8, 14473.

(112) Ranallo, S.; Prévost-Tremblay, C.; Idili, A.; Vallée-Bélisle, A.; Ricci, F. Nat. Commun. 2017, 8, 15150.

(113) Rossetti, M.; Ranallo, S.; Idili, A.; Palleschi, G.; Porchetta, A.; Ricci, F. Chem. Sci. 2017, 8, 914-920.

(114) Labib, M.; Sargent, E. H.; Kelley, S. O. Chem. Rev. 2016, 116, 9001-9090.

(115) Felix, F. S.; Angnes, L. Biosens. Bioelectron. 2018, 102, 470478.

(116) Patris, S.; Vandeput, M.; Kauffmann, J.-M. TrAC, Trends Anal. Chem. 2016, 79, 239-246.

(117) Turner, A. P. Chem. Soc. Rev. 2013, 42, 3184-3196.

(118) Wei, W.; Zhang, L.; Ni, Q.; Pu, Y.; Yin, L.; Liu, S. Anal. Chim. Acta 2014, 845, 38-44.

(119) Tiwari, J. N.; Vij, V.; Kemp, K. C.; Kim, K. S. ACS Nano 2016, $10,46-80$.

(120) Arduini, F.; Micheli, L.; Moscone, D.; Palleschi, G.; Piermarini, S.; Ricci, F.; Volpe, G. TrAC, Trends Anal. Chem. 2016, 79, 114-126.

(121) Rackus, D. G.; Shamsi, M. H.; Wheeler, A. R. Chem. Soc. Rev. 2015, 44, 5320-5340.

(122) Vallée-Bélisle, A.; Ricci, F.; Uzawa, T.; Xia, F.; Plaxco, K. W. J. Am. Chem. Soc. 2012, 134, 15197-15200.

(123) Mahshid, S. S.; Camiré, S.; Ricci, F.; Vallée-Bélisle, A. J. Am. Chem. Soc. 2015, 137, 15596-15599.

(124) Mahshid, S. S.; Ricci, F.; Kelley, S. O.; Vallée-Bélisle, A. ACS Sensors 2017, 2, 718-723.

(125) Mahshid, S. S.; Vallée-Bélisle, A.; Kelley, S. O. Anal. Chem. 2017, 89, 9751-9757.

(126) Fu, J.; Yang, Y. R.; Dhakal, S.; Zhao, Z.; Liu, M.; Zhang, T.; Walter, N. G.; Yan, H. Nat. Protoc. 2016, 11, 2243-2273.

(127) Fu, J.; Yang, Y. R.; Johnson-Buck, A.; Liu, M.; Liu, Y.; Walter, N. G.; Woodbury, N. W.; Yan, H. Nat. Nanotechnol. 2014, 9, 531536.

(128) Erkelenz, M.; Kuo, C.-H.; Niemeyer, C. M. J. Am. Chem. Soc. 2011, 133, 16111-16118.

(129) Schoffelen, S.; Van Hest, J. C. M. Curr. Opin. Struct. Biol. 2013, 23, 613-621.

(130) Wilner, O. I.; Weizmann, Y.; Gill, R.; Lioubashevski, O.; Freeman, R.; Willner, I. Nat. Nanotechnol. 2009, 4, 249-254.

(131) Fu, J.; Liu, M.; Liu, Y.; Woodbury, N. W.; Yan, H. J. Am. Chem. Soc. 2012, 134, 5516-5519.

(132) Zhao, Z.; Fu, J.; Dhakal, S.; Johnson-Buck, A.; Liu, M.; Zhang, T.; Woodbury, N. W.; Liu, Y.; Walter, N. G.; Yan, H. Nat. Commun. 2016, 7, 10619.

(133) Timm, C.; Niemeyer, C. M. Angew. Chem., Int. Ed. 2015, 54, 6745-6750.

(134) Zhang, Y.; Ge, J.; Liu, Z. ACS Catal. 2015, 5, 4503-4513.

(135) Wheeldon, I.; Minteer, S. D.; Banta, S.; Barton, S. C.; Atanassov, P.; Sigman, M. Nat. Chem. 2016, 8, 299-309.

(136) Idan, O.; Hess, H. ACS Nano 2013, 7, 8658-8665.

(137) Linko, V.; Eerikainen, M.; Kostiainen, M. A. Chem. Commun. 2015, 51, 5351-5354.

(138) Zhang, Y.; Tsitkov, S.; Hess, H. Nat. Commun. 2016, 7, 13982.

(139) Küchler, A.; Yoshimoto, M.; Luginbühl, S.; Mavelli, F.; Walde, P. Nat. Nanotechnol. 2016, 11, 409-420.

(140) Grossi, G.; Jaekel, A.; Andersen, E. S.; Saccà, B. MRS Bull. 2017, 42, 920-924. 
(141) Shi, J.; Wu, Y.; Zhang, S.; Tian, Y.; Yang, D.; Jiang, Z. Chem. Soc. Rev. 2018, 47, 4295-4313.

(142) Zhang, Y.; Hess, H. ACS Catal. 2017, 7, 6018-6027.

(143) Juul, S.; Iacovelli, F.; Falconi, M.; Kragh, S. L.; Christensen, B.; Frøhlich, R.; Franch, R.; Kristoffersen, E. L.; Stougaard, M.; Leong, K. W.; Ho, Y.-P.; Sørensen, E. S.; Birkedal, V.; Desideri, A.; Knudsen, B. R. ACS Nano 2013, 7, 9724-9734.

(144) Franch, O.; Iacovelli, F.; Falconi, M.; Juul, S.; Ottaviani, A.; Benvenuti, C.; Biocca, S.; Ho, Y.-P.; Knudsen, B. R.; Desideri, A. Nanoscale 2016, 8, 13333-13341.

(145) Vindigni, G.; Raniolo, S.; Ottaviani, A.; Falconi, M.; Franch, O.; Knudsen, B. R.; Desideri, A.; Biocca, S. ACS Nano 2016, 10, 5971-5979.

(146) Kim, S. H.; Kim, K. R.; Ahn, D.; Lee, J. E.; Yang, E. G.; Kim, S. Y. ACS Nano 2017, 11, 9352-9359.

(147) Grossi, G.; Dalgaard Ebbesen Jepsen, M.; Kjems, J.; Andersen, E. S. Nat. Commun. 2017, 8, 992.

(148) Sprengel, A.; Lill, P.; Stegemann, P.; Bravo-Rodriguez, K.; Schöneweiß, E. C.; Merdanovic, M.; Gudnason, D.; Aznauryan, M.; Gamrad, L.; Barcikowski, S.; Sanchez-Garcia, E.; Birkedal, V.; Gatsogiannis, C.; Ehrmann, M.; Saccà, B. Nat. Commun. 2017, 8, 14472 .

(149) Collins, J.; Zhang, T.; Oh, S. W.; Maloney, R.; Fu, J. Chem. Commun. 2017, 53, 13059-13062.

(150) Zhou, L.; Liu, Y.; Shi, H.; Yang, X.; Huang, J.; Liu, S.; Chen, Q.; Liu, J.; Wang, K. ChemBioChem 2018, 19, 2099-2106.

(151) Van Nguyen, K.; Giroud, F.; Minteer, S. D. J. Electrochem. Soc. 2014, 161, H930-H933.

(152) Bugada, L. K.; Smith, M. R.; Wen, F. ACS Catal. 2018, 8, 7898-7906.

(153) Liu, Q.; Ge, Z.; Mao, X.; Zhou, G.; Zuo, X.; Shen, J.; Shi, J.; Li, J.; Wang, L.; Chen, X.; Fan, C. H. Angew. Chem., Int. Ed. 2018, 57, $7131-7135$.

(154) Ye, D.; Zuo, X.; Fan, C. H. Annu. Rev. Anal. Chem. 2018, 11, 171-195.

(155) Wang, X.; Chen, F.; Zhang, D.; Zhao, Y.; Wei, J.; Wang, L.; Song, S.; Fan, C. H.; Zhao, Y. Chem. Sci. 2017, 8, 4764-4770.

(156) Lin, M.; Song, P.; Zhou, G.; Zuo, X.; Aldalbahi, A.; Lou, X.; Shi, J.; Fan, C. Nat. Protoc. 2016, 11, 1244-1263.

(157) Pei, H.; Zuo, X. L.; Zhu, D.; Huang, Q.; Fan, C. H. Acc. Chem. Res. 2014, 47, 550-559.

(158) Lu, N.; Pei, H.; Ge, Z.; Simmons, C.; Yan, H.; Fan, C. H. J. Am. Chem. Soc. 2012, 134, 13148-13151.

(159) Yang, F.; Li, Q.; Wang, L.; Zhang, G.; Fan, C. H. ACS Sens 2018, 3, 903-919.

(160) Chen, X.; Zhou, G.; Song, P.; Wang, J.; Gao, J.; Lu, J.; Fan, C. H.; Zuo, X. Anal. Chem. 2014, 86, 7337-7342.

(161) Zhang, H.; Li, F.; Dever, B.; Li, X.; Le, X. C. Chem. Rev. 2013, 113, 2812-2841.

(162) Harroun, S. G.; Prévost-Tremblay, C.; Lauzon, D.; Desrosiers, A.; Wang, X.; Pedro, L.; Vallée-Bélisle, A. Nanoscale 2018, 10, 46074641.

(163) Zhou, H.; Liu, J.; Xu, J.; Zhang, S.; Chen, H. Chem. Soc. Rev. 2018, 47, 1996-2019.

(164) Lönn, P.; Landegren, U. Trends Biochem. Sci. 2017, 42, 504515.

(165) Koos, B.; Cane, G.; Grannas, K.; Löf, L.; Arngården, L.; Heldin, J.; Clausson, C. M.; Klaesson, A.; Hirvonen, M. K.; de Oliveira, F. M.; Talibov, V. O.; Pham, N. T.; Auer, M.; Danielson, U. H.; Haybaeck, J.; Kamali-Moghaddam, M.; Söderberg, O. Nat. Commun. 2015, 6, 7294.

(166) Hu, J.; Yu, Y.; Brooks, J. C.; Godwin, L. A.; Somasundaram, S.; Torabinejad, F.; Kim, J.; Shannon, C.; Easley, C. J. J. Am. Chem. Soc. 2014, 136, 8467-8474.

(167) Wen, G.; Ju, H. Anal. Chem. 2016, 88, 8339-8345.

(168) Zong, C.; Wu, J.; Liu, M.; Yang, L.; Yan, F.; Ju, H. Anal. Chem. 2014, 86, 9939-9944.

(169) Li, Y.; Yang, P.; Lei, N.; Ma, Y.; Ji, Y.; Zhu, C.; Wu, Y. Anal. Chem. 2018, 90, 11495-11502.
(170) Feng, S.; Sekine, S.; Pessino, V.; Li, H.; Leonetti, M. D.; Huang, B. Nat. Commun. 2017, 8, 370.

(171) Krishnan, S.; Ziegler, D.; Arnaut, V.; Martin, T. G.; Kapsner, K.; Henneberg, K.; Bausch, A. R.; Dietz, H.; Simmel, F. C. Nat. Commun. 2016, 7, 12787.

(172) Spruijt, E.; Tusk, S. E.; Bayley, H. Nat. Nanotechnol. 2018, 13, 739-745.

(173) Henning-Knechtel, A.; Knechtel, J.; Magzoub, M. Nucleic Acids Res. 2017, 45, 12057-12068. 